Plant Tissue Cult. \& Biotech. 27(1): 89-140, 2017 (June)

\title{
Tissue Culture Mediated Allelic Diversification and Genomic Enrichment of Wheat to Combat Production Constraints and Address Food Security
}

\author{
A. Mujeeb-Kazi ${ }^{*}$, Niaz Ali ${ }^{1}$, Amir Ibrahim, Abdul Aziz \\ Napar $^{2}$, M. Jamil' ${ }^{3}$, Sajjad Hussain ${ }^{4}$, Zahid Mahmood ${ }^{4}$, Roman \\ Delgado ${ }^{5}$, Victor Rosas ${ }^{5}$, Alejandro Cortes ${ }^{5}$ and S. Rajaram ${ }^{6}$
}

Texas AEM University, Texas, USA

Key words: Wide hybridization, Pre-breeding strategies, Genomic based allelic enrichment, Food security, Genetic stocks, Wheat improvement

\begin{abstract}
In view of the emerging population trends and that wheat crop is the major unequivocally recognized conduit towards addressing the food security challenges of 2050 this discourse embraces various research options that are viewed as possible solutions toward delivering those targets for providing nutritious food and meeting the aspirations that policy setters have debated on the subject for decades. The underlying strength for achieving these targets will require concerted efforts from plant researchers that are well integrated within effectively harnessing and utilizing prevalent genetic diversity of the wide array of alleles in a holistic pro-active manner. We argue that the purists of basic and strategic research dimensions need to be thoughtfully defined, so that the vital target of delivering the "applied" gains are only realized from the outputs on farmer's fields and measured by tons per hectare. In this quest, the pre-breeding disciplines "classical mode" and its recently surfaced "modified sense" are pivotal, where within the former facet "tissue culture" (TC)/artificial culturing is embodied integrally. Taken for granted, TC has been the backbone of all wide hybridization studies and has made an enormous impact on the agricultural landscape spanning over the last six decades. With its intervention significant generic and specific incompatibilities have been overcome as well as allowing

*Author for correspondence: ${ }^{1}$ Department of Botany, Hazara University, Manshera, KP, Pakistan. ${ }^{2}$ Plant Sciences Department, Quaid-e-Azam University, Islamabad, Pakistan. ${ }^{3}$ Botany Department, University of Sargodha, Sargodha, Pakistan. ${ }^{4}$ National Agricultural Research Center (NARC), Islamabad, Pakistan. ${ }^{5}$ International Maize and Wheat Improvement Center (CIMMYT), El-Batan, Mexico D.F., Mexico. ${ }^{6}$ Seeds International, Mexico DF, Mexico.
\end{abstract}


researchers to exploit the protocols for adding efficiency to breeding programs, facilitate operational technologies in running breeding programs and development of unique genetic stocks that preserve valuable allelic richness in user friendly forms for future free germplasmusage in global/private domains of plant improvement ventures.

\section{Introduction}

\section{Global population trends looking at 2050 and food security targets}

Wheat is unequivocally recognized as a universal cereal and pivotal crop for addressing the growing demands of world's food supply and projected population of 9.4 billion by 2050 . The current wheat production is around 700 million tons and to give a futuristic figure the need would be around 100,000 million tons by 2050; an increase of another 300 million tons from the existing cropland. This seems a gigantic task as the production conditions shall be far from being amenable and production constraints formidable, of which many are embedded in the complex "climate change" terminology. Yields have already plateaued and sights are eagerly set for the next "green revolution" or as anticipated by Dr. Swaminathan as an "evergreen revolution". There is hence urgency for developing innovative approaches and putting these to practical use in crop improvement. For wheat, we have seen a broad coverage of promising techniques that embraced the disciplines of mutation breeding, soma-clonal variation, intraspecific hybridization, branched ear heads, large spikes, transgenic technology, interspecific as well as intergeneric hybridization. All together, there has been unravelling and exploitation of unused allelic variation to combat complex stresses. Moreover, advances in DNA sequencing and analytical approaches have shown tremendous promise in plant improvement technology resulting in genetic stocks that are vital for adding efficiency to breeding via molecular tools leading to research partnerships across disciplines. However, these efforts are far from being over and we are in 2017. Financial resources and the multiple arrays of markers on hand offer a lot of hope. However, the proof shall lie in the simple fact that resides in yield per se output of the crop in fields with its just measure of showing a definitive per annum increase.

More time has been spent on basic and strategic research and conclusions of all such studies have guided the way forward, as to what the applied expectations are. Despite, the research is attractive and information generated is exciting but time is swiftly drifting away and future goals of plant breeding are to be determined. Production constraints are magnified around climate change and emergence of new stresses like blast resistance, heat and salinity tolerance, 
nutrient quality, yield per se, dawn of new virulent rust races as well as an array of biotic plus abiotic factors will not only seriously affect crop growth but will also threaten the conservation of cultivated land. The need is to embark on a cohesive strategy of research planning and astute partnerships that are geared to harness financial resources, generate productive outputs expediently and train a critical mass of human resources across plant science disciplines to achieve success and think beyond 2050; when in just another 5 years the populace will reach 10 billion by 2055. Since, the CIMMYT based green revolution that staggered the yield levels positively in 1967 with MEXI-PAK wheat in Pakistan; for more than 4 decades the same country still see annual yields that are not exceeding 30 million tons. Further, over the last decade and a half yields have hovered around 19 to 26 million tons and reliance is still very heavy on the 1960's era where varietal production was via introduction of international nurseries, adaptation, selection and cultivar release instead of a surge towards recombination breeding assisted by cutting edge scientific technologies. This elaborate discourse is aimed to cover the prudent use of globally produced novel genetic diversity and focuses on setting priority of what should be an efficient way to proceed. Moreover, research endeavors that will not impede the applied outputs and addresses the targets of 2050 food security vision or the plans advocated for zero hunger etc. needs to be pursued. The 2050 challenge for food security in light of the population increase is threatening, as productivity will face serious constraints imposed by climate change and the demands that have set the criteria of zero hunger program. We argue that host genetic diversity can play an important role in buffering populations against widespread epidemics and thereby, combating against prevalent yield limitations. The solution of finding 'useful variation' resides in the various gene pools of the wheat family Triticeae, and exploitation of these resources appears to be the way forward to resolve and address the imminent problems as we see them today.

\section{Harnessing useful variation: The means to achieve next green revolution or "evergreen" revolution using novel genetic resources}

Wheat gene pools have been seen as potent means to counter the narrow genetic base of conventionally developed bread wheat cultivars in global cultivation that are dominated by the abundance of T1BL.1RS wheat varieties. Hence the search has been widespread to seek unique resources that will bring in new diversity for wheat improvement. In general plant improvement protocols require genetic or allelic diversity that is paramount for varietal production. Genetic diversity within the Triticeae is spread among the three gene pools "primary, secondary and tertiary" (Jiang et al. 1994). The spectrum of exploiting 
this diversity ranges from the easiest route offered by the "primary" that advances systematically to the most complex level prevalent in the "tertiary" gene pool. The base of simplicity to complexity resides in pairing of the chromosomes of wheat genomes around their similarity. Genera and species in the primary gene pool have a chromosomal complement that is similar to the A, $\mathrm{B}$ and $\mathrm{D}$ genome constitution of wheat and their chromosomes associate or pair perfectly as bivalents i.e. 7 bivalents up to 21 bivalents where the level of association is at the diploid, tetraploid or hexaploid level thus exhibiting perfect "homology". The genetic resources of the secondary gene pool have partial genomic homology. Those in the tertiary gene pool have little to no affinity and thus hybrids of wheat with such species exhibit negligible chromosomal pairing, indicative of the lack of homoeologous closeness. Hence, in hybridization programs that require recombination between maternal and paternal chromosomes, maximum gains can be expected from the primary pool genera, less from the secondary and even lesser from the tertiary gene pool with their complexities requiring multifaceted cytogenetic manipulation protocols to facilitate gene transfers.

Maintaining genetic diversity in breeding programs is vital to ensure that production sustainability prevails and the risk of any calamities does not arise in epidemics. This has been voiced from some national programs where the CIMMYT International nurseries germplasm being sent for global evaluation. Notably, most of the CIMMYT material developed in mid-1970's from the VEERY " $S$ " heritage in Mexico carries the T1BL.1RS translocation in their pedigrees and this IRS chromatin in wheat backgrounds can recombine spontaneously (Mettin et al. 1973, Ali et al. 2016). It was in CIMMYT, Mexico, that the breeders took advantage of this translocation and combined it with spring wheats developing a line VEERY "S" having four cultivars in the pedigree, Kavkaz, Buho, Kalyansona and Bluebird where the donor of the translocation was the winter wheat KAVKAZ. The progenies from this cross led to the release of Glennson, Seri, Ures, Genaro like cultivars by 1981 and their superior performance was reported by Rajaram et al. (1983). Breeders have extensively used these lines and the translocation was transferred into many of their advanced lines for overcoming their narrow genetic base. There was hence a need to unravel diverse materials with superior production attributes that led to research groups venturing to come with up innovative approaches. In this category the field of "wide crosses" emerged and sights shifted to the three gene pools with innovative strategies to combine the resources within these pools and enrich wheat breeding. 
The potential of wide crosses was phenomenal due to the genetic diversity that the wild relatives of the Triticeae members possessed in their gene pools (Mujeeb-Kazi and Hettell 1995, Ali et al. 2016). Utilization of these wild resources was not that simple and major evidences that existed until early 1980's were from the findings of Farrer (1904), Kruse $(1967,1969,1973,1974 a, b)$ that encouraged workers in the USA and Australia to exploit this approach further to generate hybrid combinations, of which the most promising was the wheat and barley cross (Mujeeb et al. 1978, Islam et al. 1978). It was established through these studies that the conventional breeding could significantly widen the genetic base of wheat by incorporating the variation that existed within the 325 annuals and perennials species of the tertiary gene pools (Dewey 1984). Thus the "Wide crosses in wheat" research area surfaced globally with a keen interest across continental programs. The facets that this program initially focused on intergeneric hybridization, and later on to interspecific and intraspecific hybridization. At the onset also surfaced the terminology "Pre-breeding" and this was the most challenging phase of wide crosses, as it combated incompatibility barriers between genera giving genuine hybrids that were cytologically validated.

\section{Pre-breeding defined}

Pre-breeding was generally considered to fit the criteria of complex wide crosses as follows:

(a) Cross combinations that required pre- and/or post pollination hormonal manipulation treatments

(b) The crossed spikes with seed set required embryo rescue between 12 and 18 days post-pollination

(c) The excised embryos had to be plated on artificial media

(d) Plantlet regeneration that gave rise to seedlings from small ill-differentiated embryos giving adult seedlings that were self-sterile but female fertile

(e) Hybrids that resulted from the crossing were cytologically validated to possess half the chromosomal complement of the female and male parents.

In this pre-bred category wheat was crossed with genera and species from all three gene pools and hybrids with co-codominant phenology were produced. These attributes were unequivocally accepted to be genuine wide hybrids and classified as "intergenerics". Production of such intergenerics dominated the wide cross research field between 1970's up to 1990's and have been reported by Kruse (1973), Mujeeb-Kazi et al. (1978), Islam et al. (1978, 1981), Sharma and Gill (1983a, b, c), Mujeeb-Kazi and Rodriguez (1980, 1981), Mujeeb-Kazi and Bernard 
(1985), Mujeeb-Kazi and Kimber (1985), Mujeeb-Kazi and Hettell (1995) and Sharma (1995).

Over the years of complex hybrids formation, emphasis shifted to embark on the practical value of this research area. The success of the spontaneous rye translocation (T1BL.1RS) was another factor that necessitated practical outputs from these alien combinations and thus choice of the alien sources was an important factor in wide crossing and maintaining the characteristics of prebreeding. As such the diploid progenitors of wheat in the primary gene pool were selected and on the scene came "interspecific hybridization". The A genome donor was T. urartu, T. boeoticum and T. monococcum, the B genome donor was focused on the Sitopsis section and the D genome donor was Ae. tauschii; all diploids i.e. $2 n=2 x=14$. These three groups of diploids were hybridized with durum wheats to produce synthetic hexaploids. The D genome synthetics exhibited perfect homologous chromosome pairing and were produced in excessive numbers. Their production details have all been discussed in MujeebKazi and Asiedu (1990) and Mujeeb-Kazi and Hettell (1995). The D genome popularity also was identified by the group in Kansas and instead of the synthetic route that possessed the user-friendly character in their programs; they resorted to exploit the diploid source via direct crosses (Gill and Raupp 1987). Breeders were somehow more interested in using the $\mathrm{D}$ genome synthetics ( $\mathrm{SH}^{\prime} \mathrm{s}$ ) in their programs as these could be crossed onto recipient wheat cultivars and allowed perfect recombination across all three genomes of the synthetic. Therefore, these SH's were considered more amenable to address and stay ahead of the global mega-environmental shifts and to outsmart crops performance in fields. Thus for practical expanded breeding targets, crosses between wheat cultivars and D genome synthetic hexaploids was the preferred choice, that encompassed both the interspecific hybridization (use of the D genome) and intraspecific hybridization (use of the A and B genomes) thereby, covering recombination events across all three genomes suited for wheat breeding. The stage was now set for wide cross based breeding around innovative ideas to widen the genetic pool of the existent wheat germplasm.

Genetic restoration via distant hybridization, "pre-breeding" with exotic sources and use of additional exotic resources that do not fit the pre-breeding category but are also significant

From the discovery of the first fertile Triticale by Rimpau 1872 intergeneric hybridization as the means to widen the gene pool was contemplated. The initial efforts of Farrer (1904) with wheat and barley did not deliver what was expected but the effort was reported. Subsequent attempts of Kruse (1967, 1969, 1973) 
overcame the incompatibility in intergeneric crosses. Bates and Deyoe (1973) proposed the use of immunosuppressants to overcome genera incompatibility but the classical confirmation of genuine hybridization came later with the reports of Mujeeb-Kazi et al. (1978) and Islam et al. (1978) where the barley/wheat hybrids possessed the full gametic chromosome complement of barley $(n=7)$ and wheat $(n=14$ or $n=21)$ a fact that was not present in derivatives of crosses between alien species with use of immunosuppressants causing that strategy to wither away by early 1980's. Kruse (1973) had used hormones in intergeneric hybrid production and these were well used by all the researchers that undertook wide crossing as success was significant. The use of 2,4-D as a pre-pollination treatment and $\mathrm{GA}_{3}$ as post-pollination, distinctly showed their effect on nucellar tissue enlargement plus prolonging the life of the seed on the crossed spikes that allowed few extra days for maternal nourishment and growth of the intergeneric embryos. The research groups in Mexico (CIMMYT) and Kansas (USA) have pursued intergeneric hybridization since 1982 and extended the range of success phenomenally where, interesting combinations beyond the wheat/Thinopyrum category were made as reviewed by Dewey (1984) and reported by Mujeeb-Kazi (1982) Sharma and Gill (1983a,b,c). The following decade marked glaring wide hybridization outputs (Mujeeb-Kazi and Bernard 1985, Wang 1989, Jiang et al. 1994, Mujeeb-Kazi and Hettell 1995) prompting the paper by Sharma 1995 entitled "How wide can a wide cross be". Successful hybrids between wheat cultivars and the tertiary gene pool genera/species were developed using the hybridization protocol. The characteristics of "prebreeding" were consolidated, defined and wide crosses had become rather simplified. Use of exotic sources for wheat improvement was routinely exercised but the practical outputs of all programs still eluded. It was this applied objectivity that led the diversification of wheat with exotic primary gene pool sources and the immense potential of Aegilops squarrosa syn. tauschii $(2 \mathrm{n}+2 \mathrm{x}=14$; DD) was highlighted. Cox and Hatchett (1994), Cox et al. (1990, 1994, 1995a, b) had exploited this germplasm accessions via direct crosses, and the CIMMYT group initiated a random procedure of combining the above source with various durum wheats $(2 \mathrm{n}=4 \mathrm{x}=28$, AABB) to generate hexaploids "synthetics" ( $2 \mathrm{n}=6 \mathrm{x}$ $=42$, AABBDD). Remarkable success of this route with the $\mathrm{D}$ genome, the diploid donors of the $\mathrm{A}$ and $\mathrm{B}$ genomes were also hybridized and the range of diversity across all three genomes in terms of synthetic hexaploids was produced in abundance. This allowed breeding programs to tap on preferred sources of diversity for resistance /tolerance identified in these SHs. The D genome SHs had a mighty impetus than the A and B genome hexaploids due to their quantity and ability to tolerate stresses and deliver quality traits, and that continues to this day (Mujeeb-Kazi 2003). The grouping of SH wheats into sub-sets was accomplished 
to serve global interests in a focused manner and let researchers to consolidate on potential lines, rather than to screen the entire SH collection of over a 1000 entries. Further, this material was widely distributed in the form of seed nurseries as elite $1 \mathrm{SH}^{\prime}$ s and elite $2 \mathrm{SH}^{\prime}$ s. Additive to these, on personal requests sub-sets of SH entries were tested and found promising for drought, heat, salinity, water logging, head scab. rust resistance, BYDV, spot blotch, Septoria, karnal bunt, grain quality, 1000 kernel weight, CCN, tan spot, mildew, micronutrient levels etc. This had set the stage for extensive utilization of the $\mathrm{D}$ genome SH's in a global pursuit; although until now the true potential of these D genome $\mathrm{SH}^{\prime}$ 's remains under-exploited.

All initially developed SH's were of the spring growth habit, latter Cox et al. (1995a, b) had ventured crossing onto winter wheats, a program that did not capture substantial breeder appeal. It was only nearly two decades when up to a hundred winter synthetics were produced from crosses of winter durums and Ae. tauschii and shared globally and since then winter synthetics have got practical recognition (Ogbonnaya et al. 2013).

Though practical agricultural outputs of wide crosses was a major factor in shifting from the tertiary to the primary (Ae. tauschii) and secondary gene pool (Ae. speltoides), maintaining of the pre-breeding mode remained integral in either case. Other factor that led to the diversification and search for additional unique options was the prevailing criticism that conventional wheats had a narrow genetic base and most of the leading wheat germplasm from CIMMYT distributed had the T1BL.1RS translocation in their pedigree. The way these wheats were bred was the innovative combination of winter wheat KAVKAZ with spring wheat and this increased our arsenal of winter/spring crosses. This was a deviation from the classical pre-breeding concept and it did play a significant role in looking at other exotic sources that could be used in wide cross. Researchers should consider this endeavor, which would encourage the conventional breeders to embark on additional means of wheat improvement as a renewed source of diversity. Thus instead of the earlier well-known intraspecific durum/wheat route, different tetraploids and hexaploids were entertained in hybridization and this is where the term pre-breeding got distorted.

\section{Usage and attributes of intraspecific, interspecific and intergeneric hybridization mediated by artificial culture intervention}

With the widening of the wheat gene pool, the stage was set for defining

wide crosses and categorization of intergeneric, interspecific and intraspecific hybridizationareas as well as description of "pre-breeding" emerged. We propose 
that wherever hybridization required tissue (embryo) culture, was mandatory to use laboratory/greenhouse facilities those areas to be classed under pre-breeding. This clearly delineates the erroneous usage of pre-breeding for primary gene pool tetraploids and hexaploids that can be easily crossed under field conditions and do not require controlled environmental facilities or special handling protocols. Generally all Triticeae sources of the tertiary gene pool fall in this category of pre-breeding. The notable exceptions that had been reported were the combinations with Thinopyrum species like acutum, intermedium, pulcherrimum, trichophorum, varnense (Mujeeb-Kazi et al. 1987) where hybridization was a field operation but needed pre- and post- pollination hormonal treatments.Viable seed set were reported despite of the fact that the hybrids later exhibited a co-dominant phenotype, were self -sterile $(2 n=6 x=42)$ and cytologically with predominant univalent meiotic association characterizing lack of wheat/alien chromosome pairing.

\section{Intraspecific hybridization}

Intraspecific hybridization is characterized by crosses between wheat and alien sources that share chromosomal homology. This allowed breeders to conduct hybridization under field conditions without a need for laboratory facilities or tissue (embryo) culture. This facet of hybridization is not emphasized in this coverage as dealt here is what falls into the pre-breeding category. Included in this categorization would be the production of hexaploid and octoploid triticales where durum wheat/rye or hexaploid wheat/rye require environmental control and special attention like colchicine induced doubling to restore fertility. The other well known sources are T. timopheevi, $T$. dicoccon, T. dicoccoides, T. carthlicum, T. polonicum that can be directly crossed onto durums and as pollen parents onto bread wheat to implement the pentaploid wheat breeding route. Currently preferred is the under-exploited use of accessions of T. polonicum notably due to its large bold grain. Among the hexaploids like $T$. zhukovskii, T. carthlicoides and T. spelta currently more interest is attached to $T$. spelta. Although, significant practical returns from these approaches are still awaited both for durums as well as for bread wheat. The potential is however high, as due to chromosomal homology between the A, B and A, B, D genomes, recombination events are likely to take place. Crossing success are higher when bread wheat is used as a female parent and the tetraploid as pollen donors. The F1 so produced may be shriveled in its seed appearance but the embryo viability is high. The seedlings are pentaploid $(2 \mathrm{n}=5 \mathrm{x}=35, \mathrm{ABDAB})$ and can be back crossed or allowed to self where the derivates eventually end up in euploid for durum or bread wheats and have been in usage for wheat breeding and 
improvement. This classical intraspecific area has currently reduced as the D genome synthetics provide this pentaploid option and simultaneously allow the D genome recombination, thus breeding programs are relying more for such routes called "bridge crossing" that took emphasis from early 1990's and is still widely advocated.

\section{Interspecific hybridization}

Interspecific hybridization has gained promise since the potential of $\mathrm{D}$ genome synthetics was revealed. Success of T. turgidum crossed with $T$. tauschii or Ae. tauschii resides as their product "synthetic hexaploids" are fertile derivatives that extend the usage into breeding for new wheat varieties following bread wheat/SH crossing. SH's have not been used for durum improvement; although, possibility exist and the crossed product would be a pentaploid hybrid that can be exploited to generate durums as well new bread wheats.

A unique strategy under exploited for durum improvement is via direct durum/D genome diploid cross. In this case the durum would be Cappelli ph1c mutant as the female parent pollinated by Ae. tauschii accession resulting in an $\mathrm{AB}$ (ph1c) D hybrid where the preferential pairing would be between the A and the D genome chromosomes up to the extent of 7 bivalents (Fig. 1)

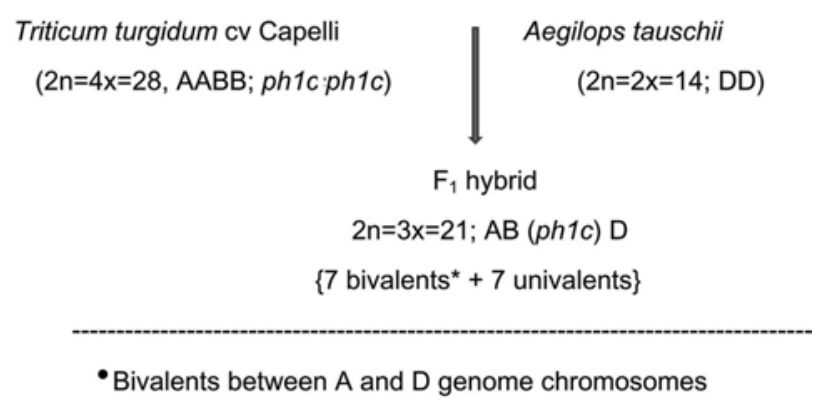

Fig. 1. Usage of durum wheat Capelli with ph1c ph1c to promote A and D genome pairing and transfers where hybrid shows 7 bivalents and 7 univalents at meiosis. Pairing is between the $\mathrm{A}$ and $\mathrm{D}$ genome chromosomes identified separately via differential staining.

\section{Intergeneric hybridization}

Initially, all intergeneric hybridization posed considerable complexity that, were simplified during the $70^{\prime} \mathrm{s}$ and $80^{\prime} \mathrm{s}$ as regards to production of cross combinations. The outputs in terms of practical products are still not that plentiful, as most of such hybrids do not exhibit wheat/alien chromosomal associations at meiosis in $\mathrm{F}_{1}$ hybrid. Pairing has to be induced via complex cytogenetical protocols and still for traits that are polygenic the ultimate 
desirable results are still awaited. Useful variation is abundant for all stresses (biotic and abiotic) in these wild species but their control is also distributed across many alien chromosomes. Hence it has been quite recently that the choice of the alien parent for intergeneric unison is stringently made for which, the diploid alien genera like Th. bessarabicum, L. elongatum, Haynaldia villosa, Secale cereale are preferred, all have been successfully hybridized and have given recombined partially finished products (Mujeeb-Kazi et al. 2013).

Relatively recent programs have given great emphasis on utilizing the diversity of tertiary gene pool genera/species. Nonetheless, excessive use of $S$. cereale has also been taken up. These efforts indeed add to our understanding but efforts of the last three decades and the need to deliver practical outputs by 2050 priorities and choice of using "ideal" alien donor parent should be carefully weighed. This may not hinder utilization of the Ae. tauschii D genome SH's where over a 1000 SH's are available and enough is known of their accessional traits. Further, the $\mathrm{D}$ genome $\mathrm{SH}^{\prime}$ s allows direct transfer of useful traits as chromosomal segments but the use of this valuable material has been abandoned since the last two decades. It is appropriate to recognize that for food security and the projected 2050 vision, high yielding varieties with good stress resistances/tolerances are to be developed "swiftly". To stay ahead in this race, a technology referred to as "doubled haploidy" is available but that has not been excessively used in public sector. This technique allows efficiency across several facets of research sectors and apart from its application exclusively to yield homozygous derivatives it is equally suitable for a breeding target, and shortens the time span remarkably.

We propose that the ideal choice of alien donor parent for wheat improvement should be based on practical outputs that are yield oriented under field conditions. This separates the basic/strategic areas of wide crosses from the applied transparently. The targets of 2030 for zero hunger and 2050 of food security may not allow researchers to exercise the luxury of using alien resources that are complex to handle, or instead allowing segregating progenies that are quality compromised. Experimentally proven guidelines for the choice of alien sources is well documented and the germplasm holdings are gauged. Time spent and the benefits derived from research efforts while using tertiary gene pools are curtailed as compared to the use of easy to cross primary gene pool tetraploids, hexaploids. We reason to believe that such efforts are more likely "one step in the forward direction and ten in the reverse". Such luxury of basic/strategic research at this time, we consider best deferred and the germplasm holdings that are globally available need exploitation in the first place. Setting aside S. cereale in lieu of globally available translocation stocks will be more prudent and avoiding 
easy tocross primary pool genera and accessions of $\mathrm{D}$ genome synthetics be more appropriate. Achieving additional 300 million tons of wheat by 2050 for the populace needs would be more likely possible by using the $\mathrm{D}$ genome resources than focusing on diversity of land races, new intergenerics with tetraploid and polyploid triticeae genera. Similarly, instead of tagging traits to rye based new crosses the use of wheat/rye translocations on hand would be more desirable.

\section{The pivotal role of tissue culture in wide crosses and wheat improvement}

Tissue culture (Embryo) has made an enormous impact on almost all prebreeding endeavors of wheat wide crosses. Moreover, the role of tissue culture has been instrumental in the development of fertile hybrids through doubled haploid technology and in introducing new varieties with higher yields, which are better adapted to changing farming systems and user demands.

The most significant effects of tissue culture (embryo) in strategic wheat wide cross research has been the phenomenal surge that emanated during mid1980's in Kansas State (Wheat/Ae. tauschii direct crosses) and in CIMMYT, Mexico (bridge crossing combination of interspecific and intraspecific hybridizations) followed by additional genetic stock development involving the A and $\mathrm{B}$ genome wild donor species. In all these endeavours after parental crossing, embryo rescue and plating in artificial media was of paramount significance for achieving success of the pre-breeding program. Such efforts have led to various interesting research options and made wild grass genetic diversity user friendly for breeders and are discussed briefly below:

\section{Direct Crosses}

Actively initiated in Kansas State (Gill and Raupp 1987) this entailed the crossing of wheat cultivars with potential Ae. tauschii accession, rescuing the F1 embryo $(2 \mathrm{n}=4 \mathrm{x}=28, \mathrm{ABD} \mathrm{D})$, seedling differentiation, its growth and then backcrossing with the wheat cultivar for putative advance lines. The strength of the procedure was in achieving genetic transfers from the accessions used into the $\mathrm{D}$ genome of wheat and leaving the $\mathrm{A}$ and $\mathrm{B}$ genomes of bread wheat unaltered during crossing; a course vital for precision research. This strategy was used in the applied arena (Cox 1997, Gill and Raupp 1987) but has yet to be exploited currently, particularly when the D genome synthetics have generated ample trait positive information allowing these accessions to be used in direct crosses; a futuristic target that needs attention and pursuing.

\section{D genome synthetics}

This can be a targeted route where the accessions of Ae. tauschii are stress screened and then crossed onto susceptible durum wheat cultivars that results in 
SH derivatives. These if resistant for the trait would imply, that the resistance trait was transferred from the Ae. tauschii accession. Unfortunately, the synthetics obtained this way in earlier rust research efforts in Canada (Ma et al. 1995) did not give display resistance, indicating that the $\mathrm{D}$ genome of the resistant $A e$. tauschii accession was silenced in the durum background by it's A and/or B genomes. Researchers in CIMMYT deviated from this targeted path and embarked on an adventurous route of attempting to hybridize all Ae. tauschii accessions in the global collections with their elite durum cultivars thus generated a vast array of $\mathrm{D}$ genome synthetic hexaploids. The philosophy was that the durum was susceptible for the stress trait and if the SH derivative was resistant then this resistance was contributed/expressed by the $\mathrm{D}$ genome chromosomes. This has proved beneficial in assigning resistance to synthetics for various traits and in some unknown areas fortuitously a SH's resistance was also assigned to the $\mathrm{A}$ and or $\mathrm{B}$ genome. This was possible as using $\mathrm{SH}^{\prime} \mathrm{s}$ in wheat breeding not only took advantage of the $\mathrm{D}$ genome of the Ae.tauschii accession (interspecific) but also to captured the diversity of the durum parent (intraspecific). This genome wide recombination has been preferred by wheat breeders particularly, in crosses where exchanges across all three genomes are sought. The SH production and usage schematics are previously illustrated but follows is a modified version in Fig. 2.

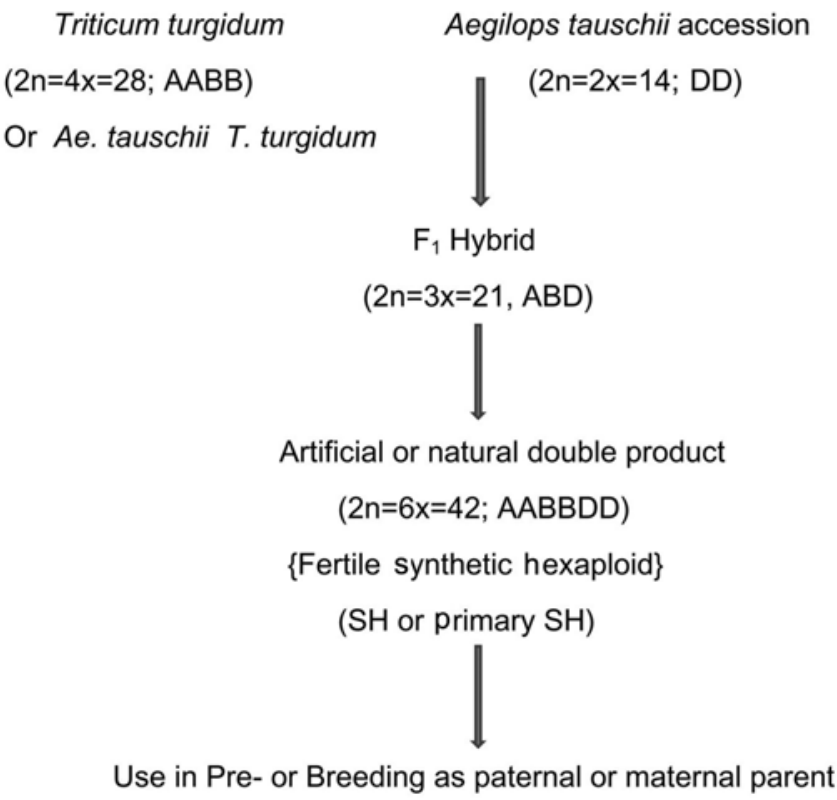

Fig. 2. Flow schematic showing the production of $\mathrm{D}$ genome synthetic hexaploid wheats; $2 \mathrm{n}=$ $6 x=42$, AABBDD from crosses between durum wheat or Aegilops taushii with the D genome diploid or by durum wheat in their parentage. 
When Ae tauschii accessions are the maternal parents in the cross, embryo recovery is phenomenally high approaching up to $80 \%$ but embryo differentiation is drastically reduced. Thus the advantage offered has not been adequately exploited, leaving room for experts to modify the culture media for harnessing the high frequency. On the other hand, when Ae. tauschii is the pollen parent the embryo success rate is low up to an approximately 25 to $30 \%$. All embryos are translucent, devoid of shape floating in the endosperm cavity but differentiation into plantlets is often as high as $90 \%$ and has thus been generally followed.

The SH quantity generated has been over 1000 (Mujeeb-Kazi 2003) and with global additivity another few hundred are available (Ogbonnaya et al. 2013). They are predominantly tall, late to mature, exhibit a co-dominant phenotype, hard lemma and palea thus hard to thresh, seed size variable and several have a 1000 kernel weight that exceeds 60 gms. The SH's have come into global usage across many sectors that cover basic, strategic and applied areas of investigation (Ogbonnaya et al. 2013). Significant impacts are widespread and the global interest in SH's is evident from the research coverage across scientific disciplines, summarized in Table 1.

Table 1. Utilization of synthetic wheat (1980-2017); Global involvement with various facets dealing synthetic hexaploid wheats showing the generated research interest during 1980 until 2017.

\begin{tabular}{|c|c|c|}
\hline S.N. & Research title & Reference \\
\hline 1. & $\begin{array}{l}\text { Genetic stability in synthetic wheat accessions: cytogenetic } \\
\text { evaluation as a support in breeding programs }\end{array}$ & Frizon et al. 2017 \\
\hline 2. & $\begin{array}{l}\text { Identification and mapping of } P m S E 5785 \text {, a new recessive } \\
\text { powdery mildew resistance locus, in synthetic hexaploid } \\
\text { wheat }\end{array}$ & Wang et al. 2016 \\
\hline 3. & $\begin{array}{l}\text { Diversity in D-genome synthetic hexaploid wheat association } \\
\text { panel for seedling emergence traits under salinity stress }\end{array}$ & Khan et al. 2016 \\
\hline 4. & $\begin{array}{l}\text { Root traits contributing to drought tolerance of synthetic } \\
\text { hexaploid wheat in a greenhouse study }\end{array}$ & Becker et al. 2016 \\
\hline 5. & $\begin{array}{l}\text { Characterization of Fusarium head blight resistance in a } \\
\text { CIMMYT synthetic-derived bread wheat line }\end{array}$ & Zhu et al. 2016 \\
\hline 6. & $\begin{array}{l}\text { Novel genetic diversity of the alien } D \text { genome synthetic } \\
\text { hexaploidy wheat }(2 n=6 x=42 \text {, AABBDD) germplasm for } \\
\text { various phenology traits... }\end{array}$ & Masood et al. 2016 \\
\hline 7. & $\begin{array}{l}\text { Chromosome variation and HMW glutenins in synthetic } \\
\text { hexaploid wheats (Triticum turgidum ssp. dicoccum/Aegilops } \\
\text { tauschii) }\end{array}$ & Daskalova et al. 2016 \\
\hline 8. & $\begin{array}{l}\text { Mapping and characterization of powdery mildew resistance } \\
\text { gene in synthetic wheat }\end{array}$ & Sharma et al. 2016 \\
\hline
\end{tabular}


9. High transferability of homoeolog-specific markers between Zehng et al. 2016 bread wheat and newly synthesized hexaploid wheat lines

10. Root water-uptake and plant growth in two synthetic Inagaki et al. 2016 hexaploid wheat genotypes grown in saline soil under controlled water

11. Breeding value of primary synthetic wheat genotypes for Jafarzadeh et al. 2016 grain yield

12. Genomic regions conferring resistance to multiple fungal Jighly et al. 2016 pathogens in synthetic hexaploid wheat

13. Genetic variation and association mapping of grain iron and Gorafi et al. 2016 zinc contents in synthetic hexaploid wheat germplasm

14. Genomic selection for increased yield in synthetic-derived Dunckel et al. 2016 wheat

15. Quality potential of synthetic-derived commercial wheat Tang et al. 2016 cultivars in south-western China

16. Comparative assessment of synthetic-derived and Ali et al. 2015 conventional bread wheat advanced lines under osmotic stress and implications for molecular analysis

17. Characterization of D-genome diversity for tolerance to Ilyas et al. 2015 boron toxicity in synthetic hexaploid wheat and in silico analysis of candidate genes

18. Line differences in Cor/Lea and fructan biosynthesis-related gene transcript accumulation are related to distinct freezing tolerance levels in synthetic wheat hexaploids

19. Assessment of the D-genome based genetic diversity of Faheem et al. 2015 drought tolerant wheat germplasm

20. Physiological factors underpinning grain yield improvements of synthetic-derived wheat in south-western China

21. Heat stress adaptation in elite lines derived from synthetic hexaploid wheat

22. Exploring the synthetic hexaploid wheat for novel sources of tolerance to excess boron

23. Molecular cytogenetic identification and phenotypic description of a new synthetic amphiploid, Triticum timococcum (AtAtGGAmAm)

24. Genetic mapping and development of near-isogenic lines with genes conferring mutant phenotypes in Aegilops tauschii and synthetic hexaploid wheat

25. Molecular characterization of the puroindoline-a and $b$ alleles in synthetic hexaploid wheats and in silico functional and structural insights into Pina-D1

26. QTLs analysis of drought tolerance at germination stage in a wheat population derived from synthetic hexaploid and opata

Yokota et al. 2015

Tang et al. 2015

Cossani et al. 2015

Emebiri et al. 2015

Miko et al. 2015

Amagai et al. 2015

Ali et al. 2015

Ashraf et al. 2015 
27. Development, identification and utilization of introgression Gu et al. 2015

lines using Chinese endemic and synthetic wheat as donors

28. Cytological, phenological and molecular characterization of Gul Kazi et al. 2015

$B$ (S)-genome synthetic hexaploids $(2 n=6 x=42$; AABBSS)

29. Genetic diversity among synthetic hexaploid wheat Das et al. 2015 accessions with resistance to several fungal diseases

30. Characterization of synthetic hexaploids derived from same Gul et al. 2015 Aegilops tauschii accessions and different durum cultivars

31. Quantitative trait locus analysis for flowering-related traits using two $F_{2}$ populations derived from crosses between Japanese common wheat cultivars and synthetic wheats

32. Molecular mapping of stripe rust resistance gene YrSE5756 in synthetic hexaploid wheat and its transfer to common wheat

33. Polyphenol oxidase activity and yellow pigment content in Aegilops tauschii, Triticum turgidum, Triticum aestivum, synthetic hexaploid wheat and its parents

34. Study of genetic diversity in synthetic hexaploid wheats using random amplified polymorphic DNA

35. Genetic mapping of race-specific stem rust resistance in the synthetic hexaploid W7984× Opata M85 mapping population

36. Assessing genetic variation for heat tolerance in synthetic wheat lines using phenotypic data and molecular markers

37. Preferential retention of chromosome regions in derived synthetic wheat lines: a source of novel alleles for wheat improvement

38. Synthetic hexaploid wheat enhances variation and adaptive evolution of bread wheat in breeding processes

39. Genome-wide association mapping for seedling and adult plant resistance to stripe rust in synthetic hexaploid wheat

40. Mapping resistance to spot blotch in a CIMMYT synthetic- Zhu et al. 2014 derived bread wheat

41. Genome-wide association for grain morphology in synthetic hexaploid wheats using digital imaging analysis

42. Resistance to wheat streak mosaic virus identified in Ruppetal. 2014 synthetic wheat lines

43. Management of wheat blast with synthetic fungicides, partial resistance and silicate and phosphite minerals

44. QTL mapping for important agronomic traits in synthetic hexaploid wheat derived from Aegiliops tauschii ssp. tauschii

45. Identification of quantitative trait loci for flowering-related traits in the D genome of synthetic hexaploid wheat lines

46. Synthetic wheat; a new hope for the hungry world

Nguyen et al. 2015

Wang et al. 2015

Li et al. 2015

Qadir et al. 2015

Dunckel et al. 2015

Sharma et al. 2014

Mclntyre et al. 2014

Li et al. 2014

Zegeye et al. 2014

Rasheed et al. 2014

Pagani et al. 2014

Ma et al. 2014

Nguyen et al. 2013

47. Synthetic hexaploids: harnessing species of the primary gene pool for wheat improvement

Rana et al. 2013

Ogbonnaya et al. 2013 
48. Variation in abscisic acid responsiveness of Aegilops tauschii and hexaploid wheat synthetics due to the D-genome diversity

49. PCR-based SNP detection for mapping of Net2, a causal D-

Matsuda et al. 2012 genome gene for hybrid necrosis in interspecific crosses between tetraploid wheat and Aegilops tauschii

50. Synthetic hexaploid lines are valuable resources for biotic Plamenov et al 2011 stress resistance in wheat improvement

51. Molecular tagging of a stripe rust resistance gene in a Qiang et al. 2010 Triticum durum-Aegilops squarrosa synthetic wheat CI191.

52. Synthetic hexaploid wheat and its utilization for wheat Yang et al. 2009 genetic improvement in China

53. Identification, gene postulation and molecular tagging of a Wang et al. 2009 stripe rust resistance gene in synthetic wheat CI142

54. Synthetic wheat-an emerging genetic resource

Trethowan et al. 2009

55. Resistance to Russian wheat aphid biotype 2 in CIMMYT Sotelo et al. 2009 synthetic hexaploid wheat lines

56. Expression of morphological and flowering time variation through allopolyploidization: an empirical study with 27 wheat synthetics and their parental Aegilops tauschii

57. Heritability, phenotypic correlation and path coefficient studies for some agronomic characters in synthetic elite lines of wheat

58. Genetic variation for quality traits in synthetic wheat germplasm

59. A synthetic wheat with 56 chromosomes derived from Triticum turgidum and Aegilops tauschii

60. Mapping of large-spike and much-kernel QTL by using a Wang et al. 2008 synthetic wheat Am3 as donor

61. Use of synthetic hexaploid wheat to increase diversity for CIMMYT bread wheat improvement

Dreisigacker et al. 2008

62. Characterization of quantitative trait loci controlling genetic variation for preharvest sprouting in synthetic backcrossderived wheat lines

63. Novel germplasm resources for improving environmental stress tolerance of hexaploid wheat

Imtiaz et al. 2008

Trethowan et al. 2008

64. Rebirth of synthetic hexaploids with global implications for wheat improvement

Mujeeb-kazi et al. 2008

65. AB-QTL analysis in winter wheat: I. Synthetic hexaploid wheat (T. turgidum ssp. dicoccoides $\times T$. tauschii) as a source of favourable alleles for milling and baking

66. Novel genetic diversity from synthetic wheats in breeding cultivars for changing production conditions

Kunert et al. 2007

van Ginkel et al. 2007 
67. Molecular mapping of resistance genes to tan spot Tadesse et al. 2007 [Pyrenophora tritici-repentis race 1] in synthetic wheat lines

68. Advanced backcross QTL analysis of a hard winter wheatx synthetic wheat population

Narasimhamoorthy et al. 2006

69. Development, utilization of introgression lines using a Liu et al. 2006 synthetic wheat as donor

70. Genetic characterization and molecular mapping of Hessian fly resistance genes derived from Aegilops tauschii in synthetic wheat

71. Identification and monosomic analysis of tan spot resistance genes in synthetic wheat lines (L. $\times$ Coss.)

72. Rapid and repeatable elimination of a parental genomespecific DNA repeat (pGc1R-1a) in newly synthesized wheat allopolyploids

73. Advanced backcross QTL analysis in progenies derived from a cross between a German elite winter wheat variety and a synthetic wheat (Triticum aestivum L.)

74. Utilization of preharvest sprouting tolerance gene of Lan et al. 2004 synthetic wheat RSP

75. Determination and evaluation of the sequence and textural effects of the puroindoline $a$ and puroindoline $b$ genes in $a$ population of synthetic hexaploid wheat

76. Seedling resistance to tan spot and Stagonospora nodorum blotch in synthetic hexaploid wheats

77. $\mathrm{K}^{+} / \mathrm{Na}^{+}$discrimination in synthetic hexaploid wheat lines: Transfer of the trait for $\mathrm{K}^{+} / \mathrm{Na}^{+}$discrimination from Aegilops tauschii into a Triticum turgidum background

78. Advanced backcross QTL analysis for the identification of quantitative trait loci alleles from wild relatives of wheat (Triticum aestivum L.)

79. The impact of synthetic wheat on breeding for stress tolerance at CIMMYT

Wang et al. 2006

Tadesse et al. 2006

Han et al. 2005

Huang et al. 2004

Gedye et al. 2004

Xu et al. 2004

Pritchard et al. 2002

Huang et al. 2003

Trethowan et al. 2003

80. Agronomic potential of synthetic hexaploid wheat-derived populations

Del Blanco et al. 2001

81. Registration of four synthetic hexaploid wheat (Triticum turgidum/Aegilops tauschii) germplasm lines tolerant to waterlogging

82. Registration of five synthetic hexaploid wheat and seven bread wheat lines resistant to wheat spot blotch

Villareal et al. 2001

Mujeeb-kazi et al. 2001a

83. Registration of ten synthetic hexaploid wheat and six bread wheat germplasms resistant to karnal bunt

Mujeeb-Kazi et al. $2001 b$

84. Characterisation of high and low-molecular weight glutenin subunits associated to the D genome of Aegilops tauschii in a collection of synthetic hexaploid wheats 
85. Physiological performance of synthetic hexaploid wheatderived populations

86. Changes in grain weight as a consequence of de-graining treatments at pre-and post-anthesis in synthetic hexaploid lines of wheat (Triticum durum $\times$ T. tauschii)

87. Inheritance in synthetic hexaploid wheat 'RSP' of sprouting tolerance derived from Aegilops tauschii

88. Construction and expression of a synthetic wheat storage protein gene

89. Conservation of the genetic variation of Triticum tauschii (Coss.) Schmalh.(Aegilops squarrosa auct. non L.) in synthetic hexaploid wheats (T. turgidum L. s. lat. $x$ T. tauschii; $2 \mathrm{n}=6 \mathrm{x}=$ 42, AABBDD) and its potential utilization for wheat improvement.

90. Differential suppression of stripe rust resistance in synthetic wheat hexaploids derived from Triticum turgidum subsp. dicoccoides and Aegilops squarrosa

91. Resistance to stripe rust in Triticum turgidum, T. tauschii and their synthetic

92. Suppression/expression of resistance to stripe rust in synthetic hexaploid wheat (Triticum turgidum $\times$ T. tauschii)

93. The effect of the " $\mathrm{D}$ " genome from synthetic wheat lines in anther culture responses.

94. Powdery mildew resistance in Aegilops tauschii Coss. and synthetic hexaploid wheats.

95. Evaluation for resistance to Pyrenophora tritici-repentis in Aegilops tauschii Coss. and synthetic hexaploid wheat amphiploids

96. Resistance to karnal bunt (Tilletia indica Mitra) in synthetic hexaploid wheats derived from Triticum turgidum $\times$ T. tauschii.

97. Inheritance of cold hardiness in Triticum aestivum $\times$ synthetic hexaploid wheat crosses

98. Chromosomal location of resistance to Septoria nodorum in a synthetic hexaploid wheat determined by the study of chromosomal substitution lines in 'Chinese Spring' wheat

99. Salt tolerance in the Triticeae: $\mathrm{K} / \mathrm{Na}$ discrimination in synthetic hexaploid wheats

100. Parental genome expression in synthetic wheats (Triticum turgidum $s p . \times T$. tauschii $s p$.) revealed by two-dimensional electrophoresis of seedling proteins.

101. Expression and inheritance of resistance to hessian fly in synthetic hexaploid wheats derived from Triticum tauschii (Coss) Schmal
Del Blanco et al.

2000

Calderini et al. 2000

Xiu-Jinet al. 1997

Anderson et al. 1996

Mujeeb-Kazi et al. 1996

Kema et al. 1995

Ma et al. 1995a

Ma et al. 1995b

Ghaemi and Sarrafi 1994

Lutz et al. 1994

Siedler et al. 1994

Villareal et al. 1994

Limin and Fowler 1993

Nicholson et al. 1993

Gorham 1990

Bahrman and

Thiellement 1987

Hatchett et al. 1981 
Various sub-sets that link with stress traits have been made and distributed and for initial usage two sets; elite 1 and 2, offer a sound start to a applied in prebreeding program. Greater curiosity as to gene penetration and expression has led researchers to make unique sub-sets that are categorized as follows:

(i) Same durum maternal/different Ae. tauschii accessions

(ii) Same tauschii accession/different durum parents, and

(iii) Durum maternal/Ae. tauschii accessions and their reciprocal combinations.

Recently (Masood et al. 2016) published their findings for a selection made of the first category. Their findings offer insight into how same durum phenology is affected by various accessions of Ae. tauschii and this opens a window that could be helpful in purifying the accessional holdings in gene banks where each accession is held as a collection. Thus implying that $\mathrm{SH}^{\prime}$ s of the same durum parent with an accession may differ as the pollen source used is from a collection and not a pure single plant derived Ae. tauschii accession.

The D genome SH's germplasm has been the most widely used global sources and considered as the major futuristic contributor to the next green evolution and is seen as the conduit to address food security projections of 2050 .

\section{The $A$ and $B$ genome synthetics}

With the initial success in the D genome production area in CIMMYT the wide cross group also ventured in diversifying to cover other donor diploids of wheat i.e. the $\mathrm{A}$ and $\mathrm{B}$ as a consequence synthetics were produced. These have not been utilized in plant improvement but are valuable stocks to enhance diversity in durum as well as bread wheat breeding.

\section{The A genome synthetics}

The A genome synthetic production schematic is elucidated (Fig. 3) despite it having been published earlier with some modifications

So far there are 194 A genome SH's (Mujeeb-Kazi 2003) but barely applied to practical usage. The SH's are tall, late maturing, easy to thresh, good fertility despite the A genome chromosomes being present in 4 doses since bivalent pairing is dominating and 21 bivalents are the norm (Fig. 3). Their applied usage would not in any way hamper either bread or durum wheat improvement efforts. The output of such a crossing would allow the A genome diversity to be unique as compared to the $\mathrm{A}$ and $\mathrm{B}$ genomes of the conventional durum parent, or the intraspecific with bread wheat where the pentaploid dominates. 


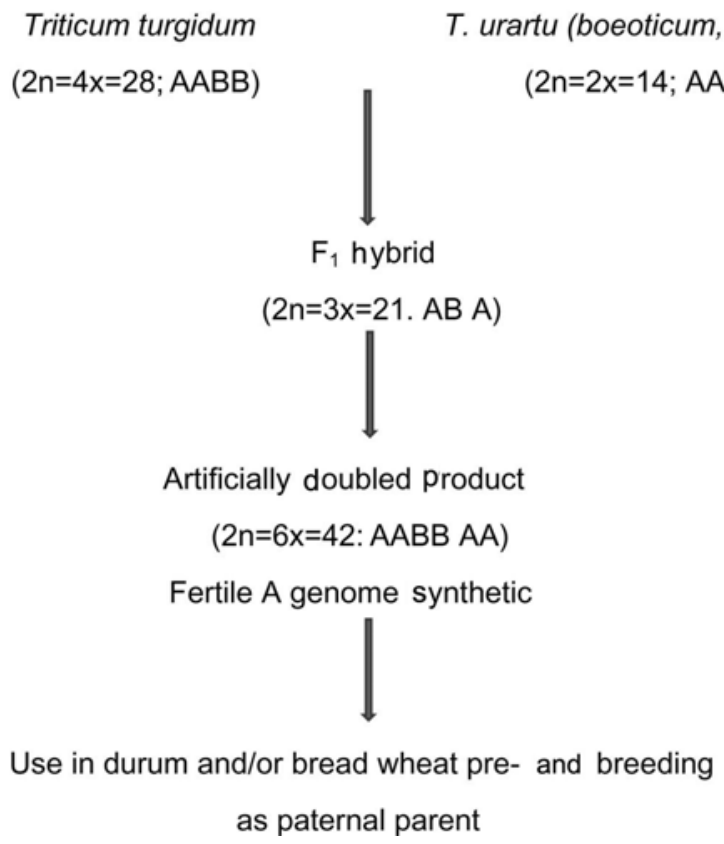

Fig. 3. Scheme showing crossing between the durum wheat with the A genome diploid progenitor to give rise to a AABBAA synthetic hexaploid.

\section{The B genome synthetics}

Crossing durum wheat cultivars with the $\mathrm{B}$ genome (Sitopsis) diploids mainly Ae. speltoides results in the $F_{1}$ hybrids that are $2 n=3 x=21, A^{3} B^{\text {s. }}$ Meiotic disruption due to suppression of the $5 \mathrm{~B}$ pairing is expected but, nevertheless was attempted in CIMMYT where these combinations were successful. The $\mathrm{F}_{1}$ was artificially doubled to give the $2 n=6 x=42$, AABB BsBs products and these synthetics fortuitously were self-fertile. Meiosis, however was not perfectly bivalent and thus seed phenotype was slightly shriveled but enough to allow seed maintenance. These B genome synthetics offer unique stocks available for futuristic breeding needs for the decades ahead. These SH's have not been utilized so far, are 54 in number (Mujeeb-Kazi 2003) and still an applied curiosity.

\section{Applied usage of the A, B and D genome synthetics in pre-breeding for varietal out-puts}

In order to meet the challenges of future food security, researchers need to use those alien accessions that have so far not been hybridized and in order to get swift practical outputs suggested in a scheme that exploits the $F_{1}$ hybrids directly in pre-breeding avoiding the artificial doubling route. The three F1's are 
genomically $\mathrm{ABD}, \mathrm{AB} \mathrm{A}$, and $\mathrm{AB} \mathrm{B}^{\text {s }}$ and if pollinated by either durum or bread wheat parents will give backcross seed set saving a whole crop cycle. Unless restitution division occur the $F_{1}$ intergeneric and interspecific hybrids are predominantly self-sterile and doubling is required to make them self-fertile thus allowing this protocol to be effective and worth trying in future when the focus is on swift practical outputs rather than only analysis of genomic behaviors.

In all the above aspects described involvement of artificial culture of immature embryos is essential for obtaining wide crosses success not only in $\mathrm{F}_{1}$ production but also in their advancement via backcrossing.

\section{Subtle variations that aid hybrid production}

Subtle variations allow wheat/alien crossing program to be more dynamic and in these some aspects cover a wide range of phenomenon. These are elucidated:

(a) The intricacies of tissue culture in furthering wide crosses efforts override overcoming incompatibility permitting unique complex cross combinations to be generated as best demonstrated by induction of diploid parental chromosome doubling exemplified by bread wheat/Psathyrostachys juncea : (Fig. 4). Backcrosses of these hybrids results inspontaneous amphiploids. This precludes obtaining direct bread wheat/diploid alien species hybrids and is a good option to circumvent $\mathrm{F}_{1}$ crossing constraints.

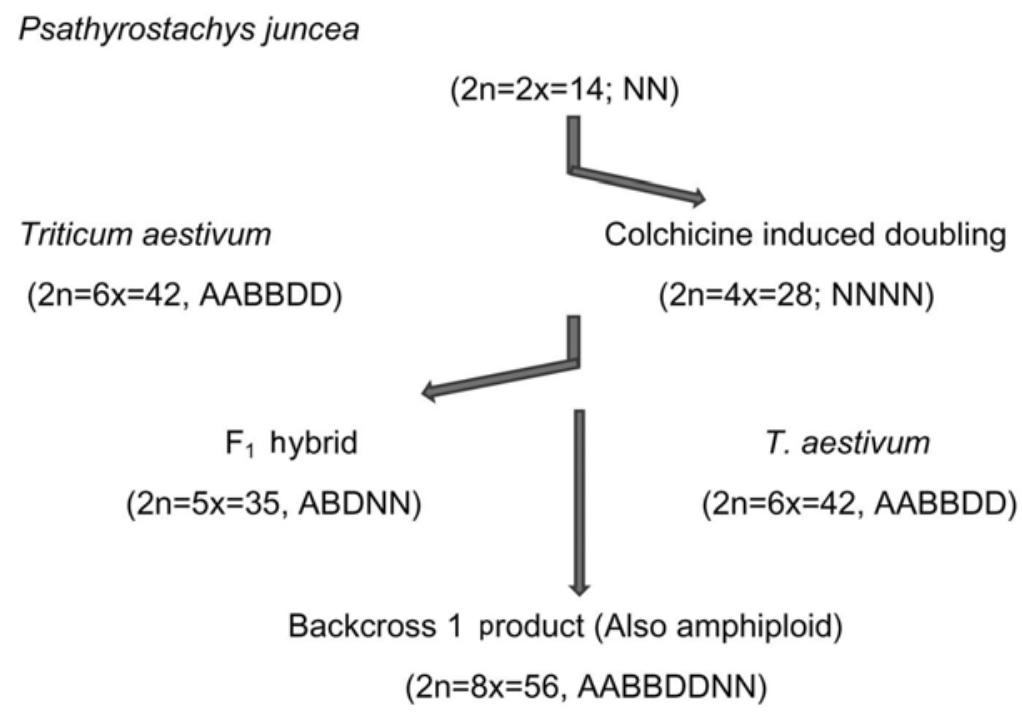

Fig. 4. Use of a colchicine doubled pollen source to facilitate crossing with bread wheat and spontaneous generation of an amphiploid upon backcrossing. 
(b) Often in cross combinations the $\mathrm{F}_{1}$ embryos are devoid of shape and their differentiation into plantlets is a constraint. Should the hybrid combination be a necessity then embryos of such combinations are plated in callus induction media, allowed to increase till green spots or embryogenic callus emerges and then use these calli to get plantlet differentiation. This process allow many plants to be derived from one embryo and the combination is thus achieved. There is a great possibility that chromosomal changes may occur but for an applied program where diversity is paramount it is a detour for a successful combination. However, keeping the short callus phase such changes may be minimized.

(c) There are two phases in exploiting the $\mathrm{F}_{1}$ hybrid combinations that are selfsterile and in both these artificial media culturing plays a pivotal role in wide cross progeny advancements. The first option is to plate embryo in a culture medim containing colchicine that permits the differentiating seedlings to double hybrid chromosome number. Such amphiploids are very valuable genetic stocks for global distribution and a huge number have been produced (Table 2a,b).

Table 2a. Details of some perennial/annual Triticeae species amphiploids with various bread wheat (Triticum aestivumL.) cultivars.

\begin{tabular}{|c|c|c|c|c|}
\hline Pedigree & $\begin{array}{l}\text { Expected } \\
\text { chromosome } \\
\text { number }\end{array}$ & $\begin{array}{l}\text { Current } \\
\text { generation }\end{array}$ & $\begin{array}{l}\text { Chromosome } \\
\text { range } \\
\text { observed }\end{array}$ & $\begin{array}{l}\text { Seed } \\
\text { amount } \\
\text { (g) }\end{array}$ \\
\hline \multicolumn{5}{|l|}{ Perennial Triticeae } \\
\hline Fremont/Thinopyrum scythicum & $2 n=10 x=70$ & C-9 & $64-68$ & 10 \\
\hline Chinese Spring (CS) /Th. podperae & $2 n=12 x=84$ & C-9 & $72-77$ & 10 \\
\hline CS/Th. bessarabicum & $2 n=8 x=56$ & C-9 & $54-57$ & 25 \\
\hline CS/Th. intermedium & $2 n=12 x=84$ & C-9 & $74-78$ & 15 \\
\hline CS/Th. trichophorum & $2 n=12 x=84$ & C-9 & $72-76$ & 15 \\
\hline $\mathrm{CS} /$ Th. junceiforme & $2 n=10 x=70$ & C-9 & $65-70$ & 10 \\
\hline Tobari 66/Th. junceum & $2 n=12 x=84$ & C-9 & $70-78$ & 5 \\
\hline $\mathrm{CS} / /$ Th. repens/A. desertorum & $2 n=10 x=70$ & C-9 & $64-70$ & 20 \\
\hline CS/Th. scirpeum & $2 n=10 x=70$ & C-9 & $68-71$ & 10 \\
\hline Pavon/Th. rechingeri & $2 n=10 x=70$ & C-9 & $69-71$ & 25 \\
\hline CS/Th. elongatum & $2 n=8 x=56$ & $\mathrm{C}-10$ & $54-57$ & 25 \\
\hline Th. elongatum/Goshawk & $2 n=8 x=56$ & C-12 & $55-56$ & 30 \\
\hline $\mathrm{CS} / \mathrm{H}$. villosa & $2 n=8 x=56$ & C-12 & $55-56$ & 12 \\
\hline \multicolumn{5}{|l|}{ Annual Triticeae } \\
\hline \multicolumn{5}{|l|}{ Chinese Spring (CS)/ } \\
\hline Aegilops variabilis & $2 n=10 x=70$ & C-11 & $64-69$ & 10 \\
\hline
\end{tabular}




\begin{tabular}{lllll}
\hline Alondra/Pavon//Ae. variabilis & $2 \mathrm{n}=10 \mathrm{x}=70$ & $\mathrm{C}-11$ & $65-70$ & 10 \\
Faisalabad/Ae. variabilis & $2 \mathrm{n}=10 \mathrm{x}=70$ & $\mathrm{C}-11$ & $66-70$ & 10 \\
Jauhar/Ae. variabilis & $2 \mathrm{n}=10 \mathrm{x}=70$ & $\mathrm{C}-11$ & $64-71$ & 10 \\
Asakazekomugi/Ae. variabilis & $2 \mathrm{n}=10 \mathrm{x}=70$ & $\mathrm{C}-11$ & $65-69$ & 10 \\
Fukohokomugi/Ae. variabilis & $2 \mathrm{n}=10 \mathrm{x}=70$ & $\mathrm{C}-11$ & $66-70$ & 10 \\
Lu 26/Ae. variabilis & $2 \mathrm{n}=10 \mathrm{x}=70$ & $\mathrm{C}-11$ & $68-70$ & 15 \\
Pak 81/Ae. variabilis & $2 \mathrm{n}=10 \mathrm{x}=70$ & $\mathrm{C}-11$ & $69-71$ & 15 \\
Punjab/Ae. variabilis & $2 \mathrm{n}=10 \mathrm{x}=70$ & $\mathrm{C}-11$ & $68-70$ & 15 \\
Sarsabz/Ae. ovata & $2 \mathrm{n}=8 \mathrm{x}=56$ & $\mathrm{C}-8$ & $55-57$ & 25 \\
Prinia/Ae. geniculata & $2 \mathrm{n}=10 \mathrm{x}=70$ & $\mathrm{C}-2$ & $66-70$ & 4 \\
Pastor/Ae. geniculata & $2 \mathrm{n}=10 \mathrm{x}=70$ & $\mathrm{C}-2$ & $66-70$ & 4 \\
Baviacora/Ae. geniculata & $2 \mathrm{n}=10 \mathrm{x}=70$ & $\mathrm{C}-2$ & $66-70$ & 4 \\
CS/Ae. geniculata & $2 \mathrm{n}=10 \mathrm{x}=70$ & $\mathrm{C}-2$ & $66-70$ & 3 \\
CS $($ phph)/Ae. geniculata & $2 \mathrm{n}=10 \mathrm{x}=70$ & $\mathrm{C}-2$ & $66-70$ & 3 \\
\hline
\end{tabular}

Table 2b. Details of some perennial/annual Triticeae species amphiploids with various durum wheat (Triticum turgidum L.) cultivars.

\begin{tabular}{|c|c|c|c|c|}
\hline Pedigree & $\begin{array}{c}\text { Expected } \\
\text { chromosome } \\
\text { number }\end{array}$ & $\begin{array}{c}\text { Current } \\
\text { generation }\end{array}$ & $\begin{array}{c}\text { Chromosome } \\
\text { range } \\
\text { observed }\end{array}$ & $\begin{array}{c}\text { Seed } \\
\text { amount } \\
(\mathrm{g})\end{array}$ \\
\hline \multicolumn{5}{|l|}{ Perennial Triticeae } \\
\hline Elymus fibrosus/Cocorit 71 & $2 n=8 x=56$ & C-9 & $55-56$ & 10 \\
\hline Altar 84/Thinopyrum scirpeum & $2 n=8 x=56$ & C-9 & $55-56$ & 10 \\
\hline Capelli/Th. acutum & $2 \mathrm{n}=10 \mathrm{x}=70$ & C-9 & $55-70$ & 20 \\
\hline Yavaros/ Th. acutum & $2 n=10 x=70$ & C-9 & $55-70$ & 20 \\
\hline Cocorit 71/ Th. acutum & $2 \mathrm{n}=10 \mathrm{x}=70$ & C-9 & $55-70$ & 20 \\
\hline Yavaros 79/Th. intermedium & $2 n=10 x=70$ & C-9 & $55-71$ & 15 \\
\hline Cocorit $71 /$ Th. intermedium & $2 \mathrm{n}=10 \mathrm{x}=70$ & C-9 & $55-68$ & 15 \\
\hline Mexicali 75/Th. intermedium & $2 n=10 x=70$ & C-9 & $55-67$ & 15 \\
\hline Capelli/Th. intermedium & $2 \mathrm{n}=10 \mathrm{x}=70$ & C-9 & $55-68$ & 15 \\
\hline Cocorit 71/Th. junceiforme & $2 n=8 x=56$ & C-9 & $55-57$ & 10 \\
\hline Cocorit 71/Th. pulcherrimum & $2 n=10 x=70$ & C-9 & $58-68$ & 10 \\
\hline Mexicali 75/Th. pulcherrimum & $2 n=10 x=70$ & C-9 & $59-71$ & 10 \\
\hline Mexicali 75/Th. podperae & $2 n=10 x=70$ & C-9 & $64-71$ & 10 \\
\hline Mexicali 75/Th. trichophorum & $2 n=10 x=70$ & C-9 & $58-70$ & 10 \\
\hline Mexicali 75/Th. varnense & $2 n=10 x=70$ & C-9 & $58-70$ & 10 \\
\hline Yavaros 79/Th. varnense & $2 n=10 x=70$ & C-9 & $58-70$ & 10 \\
\hline Capelli/Th. varnense & $2 \mathrm{n}=10 \mathrm{x}=70$ & C-9 & $67-70$ & 10 \\
\hline Arlin/Th. glaucum & $2 n=10 x=70$ & C-9 & $65-70$ & 15 \\
\hline Croc_1/Th. glaucum & $2 \mathrm{n}=10 \mathrm{x}=70$ & C-9 & $65-70$ & 10 \\
\hline Yavaros 79/Th. glaucum & $2 n=10 x=70$ & C-9 & $64-71$ & 10 \\
\hline
\end{tabular}




\begin{tabular}{|c|c|c|c|c|}
\hline Dverd_2/Th.glaucum & $2 n=10 x=70$ & C-9 & $65-69$ & 10 \\
\hline Arlin/Th. acutum & $2 n=10 x=70$ & C-9 & $65-69$ & 10 \\
\hline Altar 84//Th. acutum/Th.intermedium & $2 n=10 x=70$ & C-9 & $64-72$ & 15 \\
\hline Croc_1//Th. acutum/Th. intermedium & $2 n=10 x=70$ & C-9 & $63-70$ & 15 \\
\hline Laru//Th. acutum/Th. intermedium & $2 n=10 x=70$ & C-9 & $65-68$ & 15 \\
\hline Arlin//Th. acutum/Th. intermedium & $2 n=10 x=70$ & C-9 & $66-69$ & 15 \\
\hline Arlin_1/Th. junceiforme & $2 n=8 x=56$ & C-9 & $55-57$ & 15 \\
\hline Altar 84/Th. junceiforme & $2 n=8 x=56$ & C-9 & $54-56$ & 15 \\
\hline Croc_1/Th. junceiforme & $2 n=8 x=56$ & C-9 & $54-56$ & 15 \\
\hline Altar 84/Elytrigia pungens & $2 n=10 x=70$ & C-9 & $66-68$ & 15 \\
\hline Yavaros 79/Th. scirpeum & $2 n=8 x=56$ & C-9 & $55-56$ & 15 \\
\hline Laru/Pascopyrum spicatum & $2 n=10 x=70$ & C-9 & $65-71$ & 5 \\
\hline Dverd/ Th. trichophorum & $2 n=10 x=70$ & C-9 & $65-71$ & 10 \\
\hline Croc_1/Th. trichophorum & $2 \mathrm{n}=10 \mathrm{x}=70$ & C-9 & $65-71$ & 10 \\
\hline Rok/Kml//Th. trichophorum & $2 \mathrm{n}=10 \mathrm{x}=70$ & C-9 & $66-70$ & 10 \\
\hline Laru/Th. trichophorum & $2 n=10 x=70$ & C-9 & $65-70$ & 10 \\
\hline Altar $84 /$ Th. varnense & $2 n=10 x=70$ & C-9 & $67-71$ & 10 \\
\hline Altar 84//Th. acutum/Th.intermedium & $2 \mathrm{n}=10 \mathrm{x}=70$ & C-9 & $68-72$ & 10 \\
\hline Laru/Th. varnense & $2 n=10 x=70$ & C-9 & $67-71$ & 10 \\
\hline Dverd_2/Psathyrostachys juncea & $2 n=6 x=42$ & C-9 & $41-42$ & 25 \\
\hline Yavaros 79/Th. elongatum & $2 n=6 x=42$ & $C-3$ & $41-42$ & 25 \\
\hline \multicolumn{5}{|l|}{ Annual Triticeae } \\
\hline Laru/Aegilops variabilis & $2 n=8 x=56$ & $\mathrm{C}-7$ & $54-57$ & 15 \\
\hline Arlin/Ae. variabilis & $2 n=8 x=56$ & $\mathrm{C}-7$ & $55-56$ & 15 \\
\hline Altar/Ae. variabilis & $2 n=8 x=56$ & $\mathrm{C}-7$ & $55-56$ & 15 \\
\hline $\mathrm{Bia} /$ Ae. variabilis & $2 n=8 x=56$ & $\mathrm{C}-7$ & $55-56$ & 15 \\
\hline Ceta/Ae. ventricosa & $2 n=8 x=56$ & $\mathrm{C}-7$ & $52-57$ & 10 \\
\hline Capelli/Ae. ovata & $2 n=8 x=56$ & $\mathrm{C}-7$ & $55-56$ & 25 \\
\hline Capelli/Ae. triuncialis & $2 n=8 x=56$ & $\mathrm{C}-7$ & $53-57$ & 10 \\
\hline Capelli/Ae. speltoides & $2 n=6 x=42$ & $\mathrm{C}-7$ & $36-43$ & 5 \\
\hline Capelli/Ae. umbellulata & $2 n=8 x=56$ & $C-2$ & $53-57$ & 5 \\
\hline Mexicali_75/Ae.geniculata & $2 n=8 x=56$ & $C-2$ & $53-56$ & 5 \\
\hline $\begin{array}{l}\text { Topdy_18/Focha_1//Altar 84/Ae. } \\
\text { geniculata }\end{array}$ & $2 n=8 x=56$ & $\mathrm{C}-2$ & $53-56$ & 5 \\
\hline Cado/Boomer_33/Ae. geniculata & $2 n=8 x=56$ & $\mathrm{C}-2$ & $54-57$ & 5 \\
\hline Kucuk/Ae. geniculata & $2 n=8 x=56$ & $C-2$ & $54-56$ & 5 \\
\hline Sooty_9/Rascon_37// Ae. geniculata & $2 n=8 x=56$ & $\mathrm{C}-2$ & $55-56$ & 5 \\
\hline
\end{tabular}

(d) Should doubling be a major constraint then the self-sterile hybrid is backcrossed with wheat and handled as $\mathrm{F}_{1}$ cross. The seeds set after 12 to 18 days used for embryo rescue and generate genetic stocks as the $\mathrm{BC}_{1}$ 's are 
generally fertile. These $\mathrm{BC}_{1}$ 's have the expected chromosome number or may possess aneuploid profiles due to unique genomic shuffling. In any case artificial plating is essential. A wide array of such BC's has been produced and listed in Table 3 that are one step close for applied usage as breeders can screen these for stresses and use them for applied goal.

Table 3. Cytological details of some Triticum aestivum/perennial Triticeae $\mathbf{B C}_{1}$ self-fertile derivatives with complete and partial synthetic genomes.

\begin{tabular}{|c|c|c|c|c|c|c|}
\hline \multirow{2}{*}{$\begin{array}{l}\mathrm{BC}_{1} \\
\text { combination }\end{array}$} & \multirow{2}{*}{$\begin{array}{l}\text { Somatic } \\
\text { chromo- } \\
\text { some } \\
\text { number }\end{array}$} & \multicolumn{5}{|c|}{ Mean meiotic chromosome association } \\
\hline & & I & II (Rings) & II (Rods) & III & IV \\
\hline Nac/Th. acutum//Pavon & 56 & 1.30 & 22.80 & 4.20 & 0.10 & 0.10 \\
\hline Nac/Th. acutum//Pavon & 56 & 2.60 & 20.15 & 6.55 & $=-$ & -- \\
\hline $\mathrm{CS} /$ Th. intermedium//Buc & 56 & 3.95 & 19.75 & 5.20 & 0.25 & 0.35 \\
\hline CS/Th. intermedium//CS & 62 & 7.10 & 20.40 & 5.60 & 0.70 & 0.20 \\
\hline CS/Th. pulcherrimum// Glennson & 56 & 4.50 & 19.80 & 4.90 & 0.30 & 0.30 \\
\hline CS/Th. pulcherrimum//Pavon & 61 & 4.45 & 24.00 & 4.20 & 0.05 & -- \\
\hline CS/Th. trichophorum// Glennson & 56 & 3.20 & 19.40 & 7.00 & -- & -- \\
\hline Nacozari/Th. varnense//Fremont & 62 & 1.75 & 26.40 & 3.20 & 0.35 & -- \\
\hline Nacozari/Th. varnense//Fremont & 59 & 3.70 & 22.85 & 4.80 & -- & -- \\
\hline CS/Th. bessarabicum//Genaro & 49 & 3.40 & 19.00 & 3.50 & 0.20 & -- \\
\hline CS/Th. curvifolium//Ciano & 55 & 6.00 & 17.40 & 6.50 & 0.40 & -- \\
\hline Fld/Th. junceiforme//Ciano & 56 & 2.40 & 20.70 & 6.10 & -- & -- \\
\hline $\mathrm{CS} / /$ Th. repens/A. desertorum/3/Ciano & 56 & 6.80 & 20.20 & 4.20 & -- & 0.10 \\
\hline CS/Th. scirpeum//Ciano & 56 & 1.60 & 22.50 & 4.50 & -- & 0.10 \\
\hline CS/Th. scirpeum//Pavon & 56 & 4.80 & 17.10 & 6.80 & 1.00 & 0.10 \\
\hline CS/Th. scythicum//Fremont & 56 & 0.80 & 21.80 & 5.80 & -- & -- \\
\hline CS/Th. scythicum//Fremont & 56 & 4.20 & 17.00 & 7.20 & 0.60 & 0.40 \\
\hline Inia/Th. distichum//Inia* & 56 & 4.65 & 18.40 & 6.25 & 0.55 & 0.10 \\
\hline
\end{tabular}

(e) Often in breeding programs the freshly harvested seeds do not germinate when planted right after harvest. This is incipient dormancy and thus a fourteen days cold treatment at $4-6^{\circ} \mathrm{C}$ is helpful. This if applied to wide crosses results in subtle variation that gives over $90 \%$ differentiation of the $\mathrm{F}_{1}$ plated embryos. The plated embryos are kept in the dark under refrigerated conditions $\left(4-6^{\circ} \mathrm{C}\right)$ for $15-21$ days and then under air conditioned lab conditions in the dark until upon periodic examination the coleoptile peg is seen to emerge. At this stage the plates are given a 14/10 hrs light/dark duration to allow the seedlings to grow. This mix of cold treatment and room 
placement has provided good success in all our $\mathrm{F}_{1}$ production facets across multiple combinations covered in interspecific and intergeneric hybrid production. The interspecifics are over 1000 for the D genome, 194 for the $\mathrm{A}$ genome and 54 for the $\mathrm{B}^{\mathrm{s}}$ genome combinations. The list of intergenerics using this process has yielded a wide array of complex novel hybrids extended to cover unique trigeneric combinations (Table 4).

Table 4. Some intergeneric and trigeneric hybrids produced from crosses between Triticeae species and Triticum aestivum and T. turgidum cultivars maintained at CIMMYT, El Batan, Mexico, under greenhouse conditions as a living herbarium.

\begin{tabular}{|c|c|c|}
\hline \multicolumn{3}{|c|}{ Cross number *. Hybrid combination and chromosome status } \\
\hline \multicolumn{3}{|c|}{ Triticum aestivum/Thinopyrum species } \\
\hline B82-10824 & CHINESE SPRING/Th..acutum & $2 n=6 x=42$ \\
\hline B82-11004 & FREMONT/Th. acutum & $2 n=6 x=42$ \\
\hline B82-11058 & NACOZARI 75/Th. acutum & $2 n=6 x=42$ \\
\hline B82-10692 & CHINESE SPRING/Th. caespitosum & $2 n=5 x=35$ \\
\hline B82-10759 & CHINESE SPRING/Th..campestre & $2 n=7 x=49$ \\
\hline B82-10939 & CHINESE SPRING/Th. curvifolium & $2 n=5 x=35$ \\
\hline B81-1084 & CHINESE SPRING/Th. elongatum (10x) & $2 n=8 x=56$ \\
\hline B81-1176 & CHINESE SPRING-CNO (E)/ Th. elongatum (10x) & $2 n=8 x=56$ \\
\hline B81-1194 & NYU BAY/ Th. elongatum (10x) & $2 n=8 x=56$ \\
\hline B81-1064 & PAVON 76/ Th. elongatum (10x) & $2 n=8 x=56$ \\
\hline B81-1065 & ZARAGOZA/ Th. elongatum (10x) & $2 n=8 x=56$ \\
\hline B82-10516 & CHINESE SPRING/Th. intermedium & $2 n=6 x=42$ \\
\hline B82-10848 & GLENNSON 81/ Th. intermedium & $2 n=6 x=42$ \\
\hline B82-10656 & NACOZARI 75/ Th. intermedium & $2 n=6 x=42$ \\
\hline B82-5063 & CHINESE SPRING/Th. podperae & $2 n=6 x=42$ \\
\hline B82-10643 & CHINESE SPRING/Th. pulcherrimum & $2 n=6 x=42$ \\
\hline B82-10840 & CHINESE SPRING/Th. bessarabicum & $2 n=4 x=28$ \\
\hline B82-10780 & CHINESE SPRING/Th. junceiforme & $2 n=5 x=35$ \\
\hline B82-10990 & FIELDER/ Th. junceiforme & $2 n=5 x=35$ \\
\hline B82-10910 & FREMONT/ Th. junceiforme & $2 n=5 x=35$ \\
\hline B82-10995 & PAVON76/ Th. junceiforme & $2 n=5 x=35$ \\
\hline B82-11049 & CHINESE SPRING/ Th. juncem & $2 n=6 x=42$ \\
\hline B79-1006 & TOBARI 66/ Th. juncem & $2 n=6 x=42$ \\
\hline B82-10682 & CHINESE SPRING/Th. rechingeri & $2 n=5 x=35$ \\
\hline B82-10669 & PAVON 76/ Th. rechingeri & $2 n=5 x=35$ \\
\hline B82-5049 & CHINESE SPRING/Th, repens & $2 n=6 x=42$ \\
\hline $\begin{array}{l}\text { B82-10559 } \\
\text { to } 10585(\mathrm{C} 3)\end{array}$ & CHINESE SPRING//Th. repens. A.desertorum & $2 n=35=57$ \\
\hline B82-11042 & CHINESE SPRING/Th. scirpeum & $2 n=5 x=35$ \\
\hline B82-10865 & CHINESE SPRING/Th. sycthicum & $2 n=5 x=36$ \\
\hline$\underline{B 82-10861}$ & FREMONT/ Th. sycthicum & $2 n=5 x=35$ \\
\hline
\end{tabular}




\begin{tabular}{|c|c|c|}
\hline B82-10602 & CHINESE SPRING/Th. trichophorum & $2 n=6 x=42$ \\
\hline B82-10899 & CHINESE SPRING/Th. varnense & $2 n=6 x=42$ \\
\hline B82-10948 & NACOZARI 75/Th. varnense & $2 n=6 x=42$ \\
\hline B82-10975 & PAVON 76/ Th. varnense & $2 n=6 x=42$ \\
\hline B82-11008 & FIELDER/ Th. varnense & $2 n=6 x=42$ \\
\hline B83-4630 & CHINESE SPRING PH/Th. acutum & $2 n=6 x=42$ \\
\hline B84-4614 & CHINESE SPRING PH/Th. caespitosum & $2 n=5 x=35$ \\
\hline B84-5984 & CHINESE SPRING PH/Th. elonagtum & $2 n=8 x=56$ \\
\hline B84-5995 & CHINESE SPRING PH/Th. intermedium & $2 n=6 x=42$ \\
\hline B86-6002 & CHINESE SPRING PH/Th. trichophorum & $2 n=6 x=42$ \\
\hline \multicolumn{3}{|c|}{ T. aestivum/Haynaldia species } \\
\hline B32-2528 & CHINESE SPRING/H.villosa & $2 n=4 x=28$ \\
\hline \multicolumn{3}{|c|}{ T. aestivum/Leymus species } \\
\hline LOG82-135 & FREMONT/L.angustus & $2 n=9 x=63$ \\
\hline B82-10694 & CHINESE SPRING/L.cinereus & $2 n=5 x=35$ \\
\hline B79-1002 & CHINESE SPRING/L.racemosus & $2 n=5 x=35$ \\
\hline B82-10652 & CHINESE SPRING/L.racemosus & $2 n=5 x=35$ \\
\hline B82-10653 & CHINESE SPRING/L.triticoides & $2 n=5 x=35$ \\
\hline \multicolumn{3}{|c|}{ Thinopyron and Leymus species/T. aestivum } \\
\hline B81-1058 & Th. elongatum (10x)/BONZA & $2 n=8 x=56$ \\
\hline B80-1054 & Th. elongatum10x)/JUPATECO 73 & $2 n=8 x=56$ \\
\hline B81-1037 & L.fibrosus/PAVON'S' & $2 n=5 x=35$ \\
\hline B81-1038 & L.fibrosus/PAVON 76 & $2 n=2 x=14$ \\
\hline \multicolumn{3}{|c|}{ Elymus species/ T. aestivum } \\
\hline B81-1012A & E.agropyroides/CHINESE SPRING-CIANO (E) & $2 n=6 x=42$ \\
\hline B79-1018 & E.agropyroides/NYU BAY & $2 n=6 x=42$ \\
\hline B79-1019 & E.agropyroides/ZARAGOZA 75 & $2 n=6 x=42$ \\
\hline B81-1009A & E.dahuricus/PITIC 66 & $2 n=6 x=42$ \\
\hline \multicolumn{3}{|c|}{ Other combinations } \\
\hline B79-1009 & Th. elonagtum $(4 \mathrm{x}) /$ H.vulgare & $2 n=3 x=21$ \\
\hline B84-5982 & Th.bessarabicum/Th. junceiforme & $2 n=3 x=21$ \\
\hline B79-1008 & Th. elonagtum $(4 x) /$ S.cereale & $2 n=3 x=21$ \\
\hline LOG 80-70 & Th. trachycaulum/L.racemosus & $2 n=4 x=28$ \\
\hline LOG 80-22 & E.agropyroides/L.racemosus & $2 n=5 x=35$ \\
\hline B79-1027 & E.canadensis/H.vulgare & $2 n=3 x=21$ \\
\hline B81-1008 & Elymus sp./S.cereale (4x) & $2 n=4 x=28$ \\
\hline B79-1031 & H.vulgare/E.canadensis & $2 n=3 x=21$ \\
\hline B79-1015 & H.vulgare/E.patagonicus & $2 n=4 x=28$ \\
\hline \multicolumn{3}{|c|}{ T. turgidum/Thinopyrum (Th) species } \\
\hline B83-4316 & COCORIT71/Th. acutum & $2 n=5 x=35$ \\
\hline B83-4604 & G-803/Th. acutum & $2 n=5 x=35$ \\
\hline B83-4297 & YAVAROS79/Th. acutum & $2 n=5 x=35$ \\
\hline
\end{tabular}

(Contd.) 


\begin{tabular}{|c|c|c|}
\hline B83-4337 & COCORIT71/Th. littorale-campestre & $2 n=6 x=42$ \\
\hline B83-4346 & COCORIT71/Th. intermedium & $2 n=5 x=35$ \\
\hline B83-4438 & MEXICALI75/ Th. intermedium & $2 n=5 x=35$ \\
\hline B83-4309 & YAVAROS79/ Th. intermedium & $2 n=5 x=35$ \\
\hline B83-4373 & COCORIT71/Th. junceiforme & $2 n=4 x=28$ \\
\hline B79-1004 & COCORIT71/Th. junceum & $2 n=5 x=35$ \\
\hline B81-5036 & COCORIT71/Th. podperae & $2 n=5 x=35$ \\
\hline B83-4416 & MEXICALI75/Th. podperae & $2 n=5 x=35$ \\
\hline B83-4385 & COCORIT71/Th. pulcherrimum & $2 n=5 x=35$ \\
\hline B83-4470 & MEXICALI75/Th. pulcherrimum & $2 n=5 x=35$ \\
\hline B81-5040 & MEXICALI75/Th. scythicum & $2 n=4 x=28$ \\
\hline B83-4524 & MEXICALI75/Th. trichophorum & $2 n=5 x=35$ \\
\hline B83-4536 & MEXICALI75/Th. varnense & $2 n=5 x=35$ \\
\hline B83-4572 & G-803/Th. varnense & $2 n=5 x=35$ \\
\hline B83-4552 & CAPPELLI $p h p h /$ Th. acutum & $2 n=5 x=35$ \\
\hline B83-4545 & CAPPELLI $p h p h /$ Th. intermedium & $2 n=5 x=35$ \\
\hline B83-4546 & CAPPELLI $p h p h /$ Th. varnense & $2 n=5 x=35$ \\
\hline \multicolumn{3}{|c|}{ T. timopheevii/Thinopyrum species } \\
\hline T. timophee & /Th. elongatum (10x) & $2 n=7 x=49$ \\
\hline \multicolumn{3}{|c|}{ Thinopyrum, Agropyrum and Leymus species / T. turgidum } \\
\hline B79-1012 & Th. elongatum/COCORIT71 & $2 n=3 x=21$ \\
\hline B81-1040 & L.fibrosus/COCORIT71 & $2 n=4 x=28$ \\
\hline B80-1046 & L.fibrosus/MEXICALI75 & $2 n=4 x=28$ \\
\hline B80-1050 & L.fibrosus/QUILAFEN & $2 n=4 x=28$ \\
\hline L80-1765B & A.scabrifolium/MEXICALI75 & \\
\hline L80-1062 & A.sibericum/COCORIT71 & $2 n=4 x=28$ \\
\hline B80-1033 & A.trachycaulum/COCORIT71 & $2 n=4 x=28$ \\
\hline B80-1032 & A.trachycaulum/MEXICALI75 & $2 n=4 x=28$ \\
\hline \multicolumn{3}{|c|}{ Elymus species/ T. turgidum } \\
\hline B81-5035 & E.virginicus/COCORIT71 & $2 n=4 x=28$ \\
\hline \multicolumn{3}{|c|}{ Trigeneric hybrids } \\
\hline L80-1758B & L.fibrosus/T.turgidum//S.cereale & $2 n=5 x=35$ \\
\hline B84-6025 & E.canadensis/T.aestivum//S.cereale & $2 n=6 x=42$ \\
\hline B83-6112 & T.aestivum/Th. curvifolium// S.cereale & $2 n=6 x=42$ \\
\hline B83-6153 & T.aestivum/Th/ intermedium// S.cereale & $2 n=7 x=49$ \\
\hline B83-5269 & T.aestivum /Th. junceiforme// S.cereale & $2 n=6 x=42$ \\
\hline B84-6023 & T.aestivum /Th. pulcherrimum// S.cereale & $2 n=7 x=49$ \\
\hline B81-1255 & T.aestivum /L.racemosus//Th. elongatum & $2 n=10 x=70$ \\
\hline B81-1259 & T.aestivum/L.racemosus// T.aestivum /3/ Th. elongatum & $2 n=59-66$ \\
\hline B81-1270 & T.aestivum /L.racemosus// S.cereale & $2 n=6 x=42$ \\
\hline B81-5109 & T.timopheevii/H.bogdanii ${ }^{* * / / S . c e r e a l e ~}$ & $2 n=4 x=28$ \\
\hline
\end{tabular}

Numbering system as within the Wide Crosses Section of Mexico's living herbarium 


\section{Some facets where tissue culture mediation is an efficient means for various research spectra}

At this juncture of the presentation a broad scenario of wide crossing has been illustrated and the role of pre-breeding mediated by artificial culturing of hybrid embryos vividly shown along with some digressions to reflect standard protocol variations can add efficiency to wide crossing targets. Under discussion reveal some facets where tissue culture (embryo) mediation exemplifies the various spectra that are creatively applied for wide cross research segments and revolve around the field of plantlet homozygosity labelled as "doubled haploidy".

Remarkable achievement of rapid homozygosity has been sought via anther culture but remains a tedious process as it has not yet been refined to a stage that allows maximum efficiency across all bread wheat cultivars that play a role in a breeding program. However, wheat $\times$ maize crosses have proved beneficial and have come into fruition in wheat breeding plus other areas of wheat research (Mujeeb-Kazi et al. 2006). Several workers have successfully crossed Triticum aestivum L. with Zea mays L. (Zenkteler and Nitzsche 1984, Laurie and Bennett 1986) and Tripsacum dactyloides (Riera-Lizarazu and Mujeeb-Kazi 1993), which has led to documented production of poly haploid plants $(n=3 x=21 \mathrm{ABD})$. The essentiality of 2,4-D as a post-pollination treatment was deemed mandatory (Suenaga and Nakajima 1989). There have also been successful crosses between Z. mays and T. turgidum L. as well as other Triticum and Aegilops spp. (O'Donoughue and Bennett 1988). Successful fertilizations have also been accomplished in crosses between wheat and Sorghum bicolor L. Moench, sorghum (Laurie and Bennett 1988a, b), Pennisetum glaucum R. Br., pearl millet (Laurie 1989); Z. mays ssp. mexicana, teosinte (Ushiyama et al. 1991), Hordeum vulgare L., barley (Laurie and Bennett 1988c), and Secale cereale L., rye (Laurie et al. 1990). Crosses between wheat and the above species (as the pollen parent) provide an alternative means of producing polyhaploid (haploid if the species is a diploid) wheat plants through the natural elimination of the pollen parent's chromosomes in the early stages of embryo development. Thus, there lies unachieved possibility of exploiting the genetic variability of the diverse gene pools within these alien species for wheat improvement if, for instance, maize or Tripsacum chromosomes could actually be retained in a wheat background.

Over the last decade and a half colleagues in CIMMYT have been producing high frequencies of polyhaploid wheat plants in crosses using either maize or Tripsacum pollen. We believe that both of these polyhaploid production procedures for wheat are better than anther culture or wheat $\times$ Hordeum. 


\section{Doubled haploidy and its applications}

Polyhaploid plants are important in our efforts to reduce the number of filial breeding generations and takes to fix the homozygosity of wheat as well as other cereal plants. Homozygous plants are obtained when polyhaploid's chromosomes are doubled. This homozygosity is required in basic research as well collaborative work with partners e.g. Cornell University and the International Triticeae Mapping Initiative (ITMI) to produce molecular maps of wheat and barley genomes. Though, the major application was on wheat breeding to reduce filial research generations, the technology allowed various other options of importance to be possible as in wheat molecular cytogenetics, wide crosses and wheat transformation (Mujeeb-Kazi et al. 2006). The back-bone of all these dimensions was attributed for a good reason to the significant role of tissue culture media formulated for artificially nurturing all haploid embryos that allowed various objectives to be met successfully. Elucidating the DH role in various segments of research programs follows the brief description for immediate reference.

\section{Gene pyramiding}

The resistance seen in $\mathrm{D}$ genome synthetics is attributed to major genes that are rendered to vulnerability when such resistance is transferred into cultivated wheat varieties. More successful approach is to have varieties that possess durable resistance contributed by minor genes. However, in order to add value to the resistance of major genes in two $\mathrm{SH}$ wheats, pyramiding genes from the two diverse SH wheats with desirable and the protocol is shown (Fig. 5). Potential lines that possess cumulative resistance offered by a respective spot blotch resistant gene where each has a disease score of 2,3 on a double digit scale where 9,9 is read as total susceptibility. When two such lines with 2,3 are crossed their resultant $\mathrm{F} 1$ progeny reads 1,1 indicative of joint expressivity of the parental single dominant gene in each parental $\mathrm{SH}$ wheat. Producing sufficient doubled haploids from the $1,1 \mathrm{~F}_{1}$ population will give segregates that will show a spectral range where many 1,1 lines that could be identified and such lines have advantages for providing additive resistance conditioned by two genes instead of a single major gene. Such gene pyramiding approaches have wider application, although these genes may not be as effective as the durable resistance from minor genes but still, for surely provide a cushion to impart sustainable productivity.

\section{Production of new tetraploids}

Extending resistance across two genomes is another option where new genera can be engineered. Hybridization of accessions with resistance from A 
and $\mathrm{D}$ genomes have been hybridized to give $\mathrm{F}_{1}$ hybrid that is $2 \mathrm{n}=2 \mathrm{x}=14 \mathrm{AD}$ with 14 univalents. The hybrid upon colchicine doubling yields a novel tetraploid $(2 n=4 x=28$, AADD) with perfect 14 bivalents having full fertility and useful to be harnessed for pre-breeding facets of wheat improvement (Fig. 6)

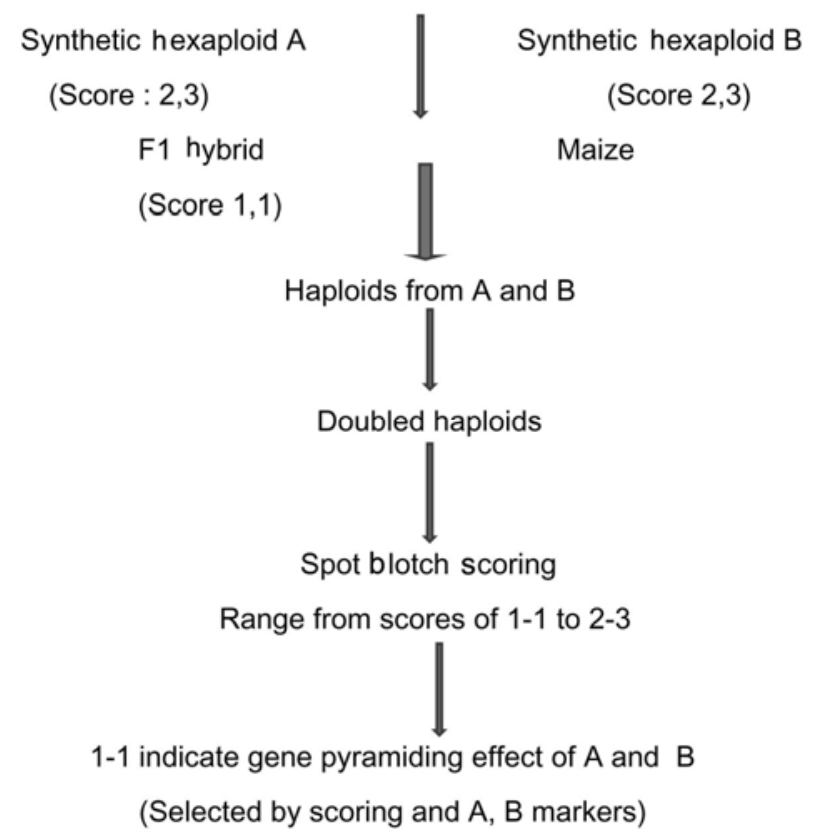

Fig. 5. Schematic show of gene pyramiding between two spot blotch resistance D genome synthetics and the potential of getting derivatives with superior resistance than either parent in their doubled haploid products.
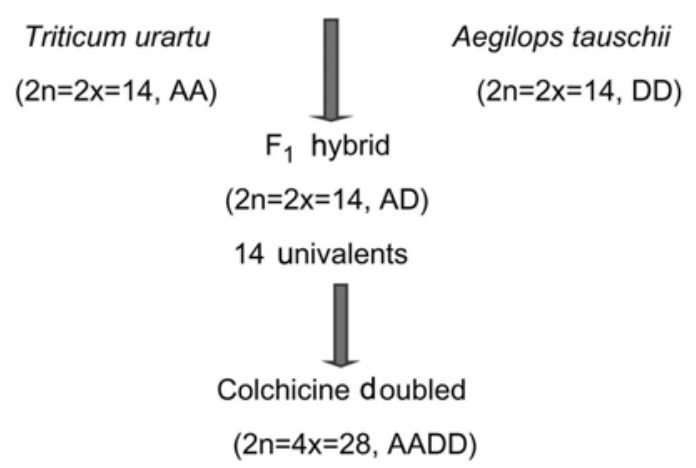

14 bivalents

(New tetraploid)

Fig. 6. Generation of new AADD tetraploid wheats by crosses between their D and A genome progenitor parents. 


\section{Production of new translocations}

In intergeneric hybrids where wheat and alien species genomes are unrelated, intergenomic transfers are infrequent due to the presence of the $\mathrm{Ph}$ locus located on chromosome 5BL of wheat. These hybrids are characterized by univalent meiosis (Mujeeb-Kazi et al. 1987, 1989). Using the $p h$ genetic stock is an option if some genomic homoeology is prevalent (Sears 1977, Sharma and Gill 1986, Jiang et al. 1994). The ph involvement can occur when the $F_{1}$ hybrid is produced (Sharma and Gill 1986) but its presence does not permit the high pairing $\mathrm{F}_{1}$ hybrid to be advanced further. We have proposed and have researched on a modified aspect of such $p h$ intervention using multiple disomics alien addition lines for salt tolerance where our findings support that the salt tolerance trait is carried by the alien chromosomes 3,4 and $7 \mathrm{E}^{\mathrm{b}}$ of the $T h$. bessarabicum. Further, full addition set of Th. bessarabicum is available and during the process of sets development multiple disomics were with 3,4 and $7 \mathrm{E}^{\mathrm{b}}$ chromosomes were identified as candidate for this $p h p h$ manipulation.

Crossing the 3, 4 and $7 \mathrm{E}^{\mathrm{b}}$ triple disomic line with Chinese Spring phph gave an $\mathrm{F}_{1}$ that was Phph heterozygote and possessed the alien chromosomes. Haploids were produced on this Phph heterozygote product and haploids with the ph locus were detected by PCR (Qu et al. 1998), doubled with colchicine, selfed a few times with the progeny then becoming a source of homoeologous and/or nonhomoeologous translocations between $\mathrm{ABD}$ and its three alien inclusions i.e. 3,4 and $7 \mathrm{E}^{\mathrm{b}}$ that await analyses (Mujeeb-Kazi 2003). The protocol steps for this kind of manipulation are elucidated (Fig. 7).

\section{Wide crosses}

In wide cross research areas, $F_{1}$ hybrids are mandatory and to exploit their full potential development of individual alien disomic addition lines are pivotal. The decades long wide cross program in CIMMYT, wide array of hybrids were produced. Several of these combinations were located in global gene banks and, amphiploids of these became a curiosity for crossing with maize and generating ample $F_{1}$ self-sterile hybrids. This information is significant for global researchers who with strong tissue culture laboratories desire to embark in wide cross research and producing hybrids with access to alien species is demanding. They can acquire these freely available amphiploids from global connections and use them to have an independent living herbarium of perennial hybrids that can be selectively used in basic, strategic and applied research areas. The protocol is elucidated in Fig. 8. 


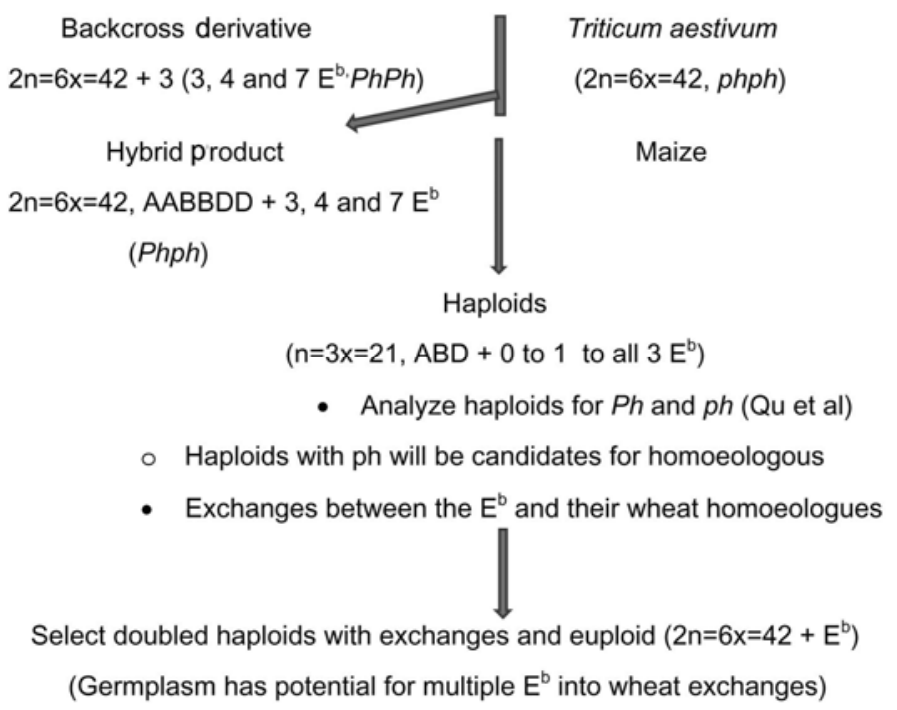

Fig. 7. Revised use of the wheat phph mutant to produce wheat alien multiple translocations between candidate alien chromosomes for a trait and their homoeologous wheat groups thus effecting en bloc trait transfers for polygenic control as is the case for salt tolerance.

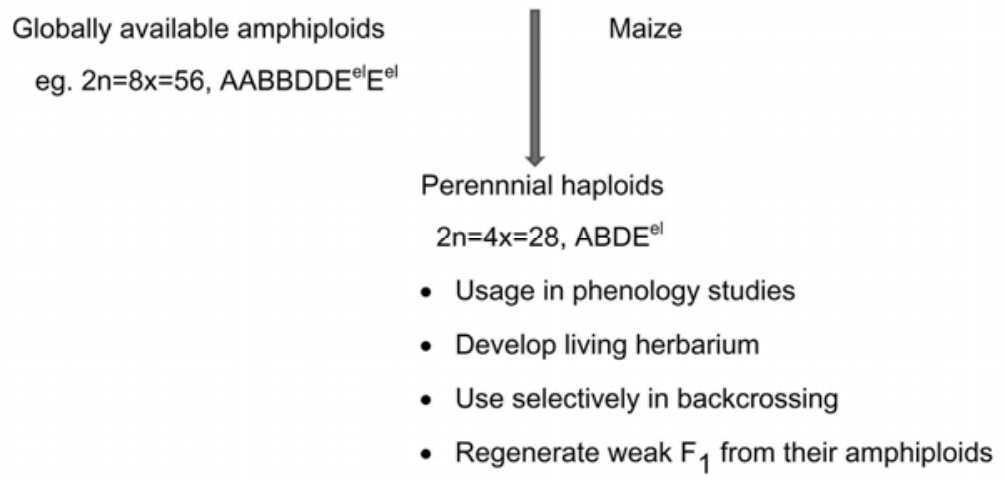

Fig. 8. Elucidatory flow of perennial haploids from their amphiploids in gene banks.

\section{Disomic addition line development}

Using the haploid protocol for alien disomic line development was demonstrated by Islam et al. (1981) and this can be readily applied in cytogeneticswhere, backcross progenies with full wheat and variable alien monosomic addition lines can be crossed with maize to generate alien monosome haploid that upon doubling will give the desired disomic addition line (Fig. 9). We propose that such addition lines may be more stable and their maintenance could be more simplistic and requires ascertaining. 


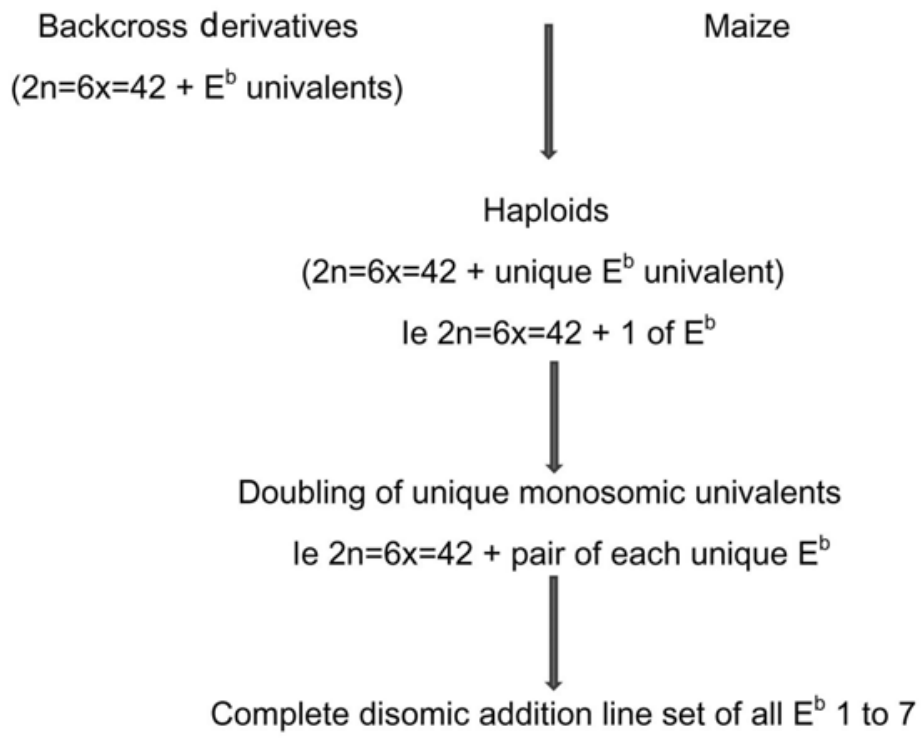

Fig. 9. Use of wheat/maize haploidy to produce alien disomic additions in a wheat background.

\section{Genetic analysis}

The doubled haploid approach is being effectively used to conduct genetic analyses and to identify physical location of genes through complete or partial monosomic analysis of which the latter is exemplified in Fig. 10. Partial analyses are conducted when resistance is associated with any one of the three genomes of the resistant synthetic wheat i.e. A, B or D. Since, resistance is being contributed by the $\mathrm{D}$ genome of donor Ae. tauschii $(2 \mathrm{n}=2 \mathrm{x}=14$; DD) accessions. For the analysis monosomic stocks of the $\mathrm{D}$ genome (1D to $7 \mathrm{D}$ or $2 \mathrm{n}=6 \mathrm{x}=40+1 \mathrm{D}$ to $7 \mathrm{D}$ ) are each crossed by the resistant synthetic to yield $F_{1}$ progeny seed as shown in the schematic Fig. 10.

Continuing the protocol where, the $\mathrm{F}_{1}$ monosomes of 1D to 7D $(2 \mathrm{n}=6 \mathrm{x}=40+$ $1 \mathrm{D}$ to $40+7 \mathrm{D})$ are crossed with maize yield 21 and 20 chromosome haploids. The 21 chromosomes haploids are selected and doubled with colchicine to yield 42 chromosome double haploids (DH). Each DH now possesses the homozygous 1D to 7D chromosomes contributed to the synthetic wheat by Ae. tauschii. Stress screening of these non-segregating resistant DH's is attributed to the presence of genes/genes in them for that particular trait. Such stable monosomic based DH's simplify conventional monosomic analyses and facilitate global distribution of stable germplasm by avoiding experimental repetition to re-build analytical germplasm as is necessary when the conventional strategy is followed (MujeebKazi et al. 2006). Applying the protocol to a complete coverage including the A and $\mathrm{B}$ genomes follows a similar extension as detailed above for the $\mathrm{D}$ genome. 


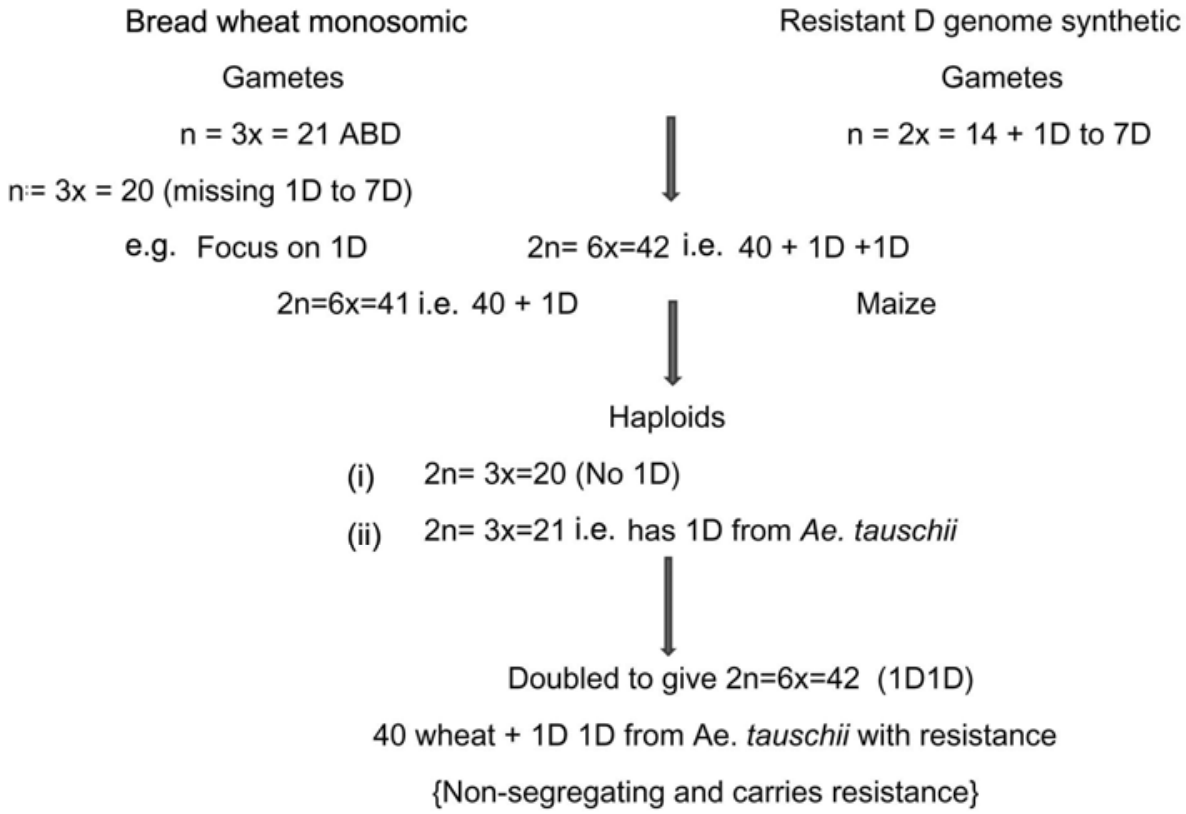

Bread wheat monosomic Gametes $n=3 x=21 A B D$ $n:=3 x=20$ (missing $1 D$ to $7 D$ )

e.g. Focus on 1D

Resistant $D$ genome synthetic

Gametes

$n=2 x=14+1 D$ to $7 D$

Fig. 10. Maize mediated partial monosomic analysis when D genome synthetic wheat is identified as resistant and this is indicted to be on 1D.

\section{Transformation}

Artificially plated embryos exposed to extraneous gene introgressions generate putative transformants. Although, these transformants are often considered to be unstable in a sense that the introduced genes expression may change due to a number of gene silencing mechanisms as explained by methylation coupled with incipient heterozygosity over several selfing cycles. Similarly, homozygous transformants may over-ride the introduced genes silencing constraint during selfing and is an extended usage of artificial plating in culture media (modified schematic Fig. 11 from Mujeeb-Kazi et al. 2006)

\section{Molecular mapping population}

Molecular mapping populations are crucial in molecular diagnostics for both phenotyping and genotyping. The standard usage applies single seed descent (SSD) procedure where, after $\mathrm{F}_{6}$ adequate recombinant inbreeding lines (RIL's) are achieved. Desired polymorphic parents upon crossing produce $F_{1}$ seed, which are then crossed with maize to generate haploid progeny. Depending upon the genetic nature of the trait (i.e. simple to polygenic inheritance) the mapping population size varies between 100 to about 250 doubled haploids per population. Their genetic stability makes these mapping populations (MP's) ideal in both phenotyping as well as genotyping areas (Fig. 12). Mujeeb-Kazi 
(2003) further suggested that MP's should be built for stress factors where one population could fit the needs of several related stresses. In order to make this functional, parental choices should utilize lines with multiple resistances and susceptibilities at the $\mathrm{F}_{1}$ developmental phase (Mujeeb-Kazi and Van-Ginkel 2004).

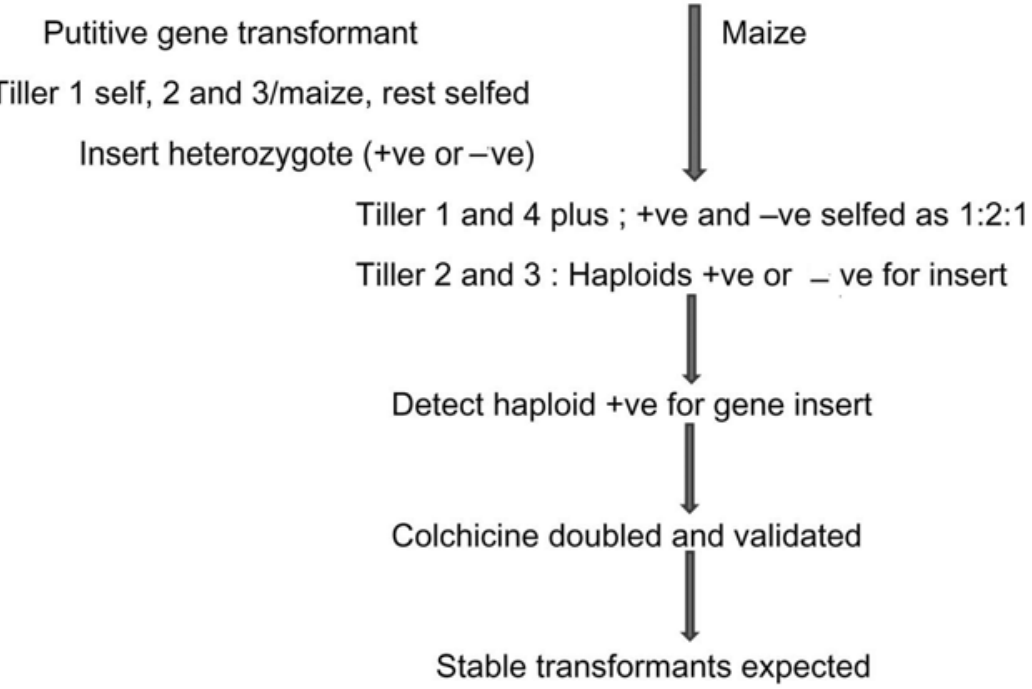

Fig. 11. Schematic showing stabilizing of transformants using the wheat/maize protocol

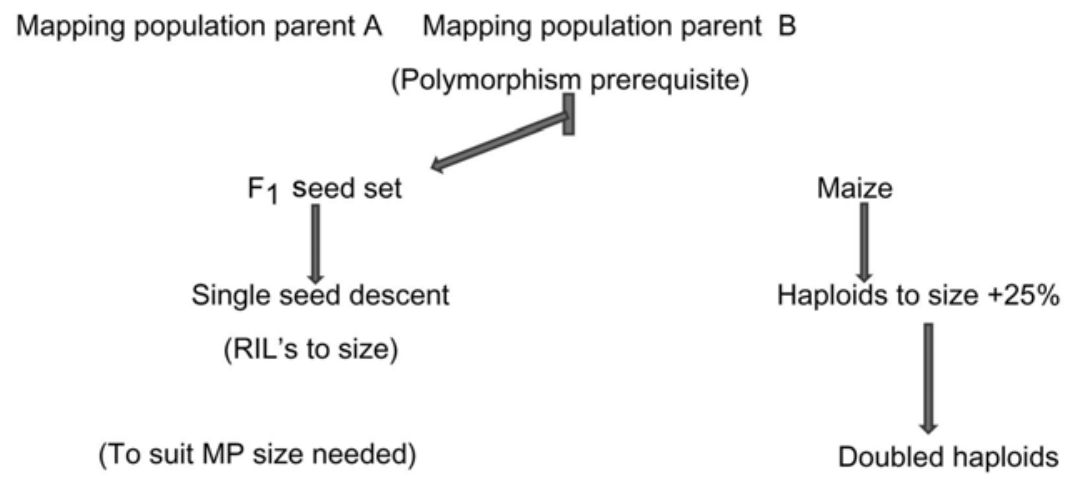

Fig. 12. Wheat/maize protocol schematic in development of molecular mapping population.

\section{Fixing heterotic vigor in commercial hybrids}

Given high importance to the applied use of $\mathrm{DH}$ for varietal development, the full potential of isolating selfed hybrid wheats ( $\mathrm{F}_{1}$ self) remains unexplored, Hybrids and their derivatives that may capture the heterotic benefits and gene pyramiding as areas of way forward perceptions. Such heterotic capture may be 
a boost to harness the $\mathrm{F}_{1}$ hybrids yields advantage in its selfed progeny and is only experimental at this stage, more theoretical but worth detailed consideration.

\section{Breeding}

Most of the conventional wheat breeding programs essentially rely on (a) presence of genetic recombination for promoting variation, (b) observing and selecting recombinants considered desirable for eventual cultivar release, and (c) advancing the selected derivatives in order to achieve homozygosity thus fixing to considerable extent all allelic variation; a phase that requires several generations beyond the $\mathrm{F}_{2}$ or $\mathrm{F}_{3}$. Final breeding steps leading to homozygosity can be hastened via artificial production of haploids where a selected promising $\mathrm{F}_{2}$ or $\mathrm{F}_{3}$ heterozygote can be made uniform in a single generation (Nei 1963). The wheat $\times$ maize technique has been perfected to such an extent where, any recombinant heterozygote can generate a haploid leading to double haploids irrespective of the wheat genotype and habit. Greater preferences in breeding programs has been for using $\mathrm{F}_{3}$ selections since, observations can be combined for good agronomic plant type, and stringent initial testing can be made for biotic stresses where rusts are usually a priority. A common constraint in several country programs is that wheat is a winter crop and maize thrives in summer. Controlled environment wheat culture is usually prohibitive due to the hot environment. For such situations stored pollen $\left(-196^{\circ} \mathrm{C}\right)$ is an option, for which pearl millet is ideal due to its viability and longevity under cold conditions (Inagaki and Mujeeb-Kazi 1994). Obtaining four to five doubled haploids per spike has been a norm across all breeding materials over our programs of the past decade and similar outputs are realized by using pearl millet stored pollen; thus assuring wide applicability of the haploidy protocol across diversebreeding programs.

The way forward to tackle the targets of 2050 food security projection and role of TC as a means of combating various emerging challenges.

\section{General perceptions and importance of haploidy in wide crosses}

All bread wheat germplasms irrespective of their growth habit respond to haploid induction using maize, or other species as pollen sources. This has made its application attractive and routine for bread wheat improvement. No genotypic specificity existent, and the current production frequencies plus costs render utilization of the technique for crop improvement across many diversified scenarios. A similar trend, however, is not present for durum wheats or TriticoSecale (Almouslem et al. 1998, Inagaki et al. 1998) but some manipulation strategies have shown a positive response (Inagaki et al. 1998). Haploid 
generation in bread wheat is independent of the source of maize pollen, but subtle preferences for the maize source do exist as for Seneca 60 and sweet corn. Researchers are using this approach extensively in various programs but are keenly waiting to replace this process with a more promising genotype nonspecific microspore culture methodology if and when it becomes readily available (Liu et al. 2002). The interest also remains in research circles to find haploid events in which maize chromosomes are present as seen in oat haploids derived from oat $\times$ maize hybridizations leading to extensive scientific information (Phillips et al. 2004). The closest to such a phenomenon in wheat haploids was the retention of one millet maize chromosome up to meiosis (Ahmed and Comeau 1990) leaving a stimulus for continuing to identify haploids retaining pollen donor chromosome/s. Currently however, the role of haploidy is being put to significant use in bread wheat breeding, cytogenetics and molecular mapping which presumably will stay prosperous for at least another decade or until another option that produces higher frequency of haploids across all genotypes emerges.

Population increases as projected and to meet the demands of 2050 for approximately 9.4 billion to have additional wheat production of 300 million tons, is a huge challenge. Even more stringent challenge is imposed by the projections of 2030 zero hunger program where, the targets are very imposing in its mandate. Wheat has been singled out as the major crop globally and thus enhancing its yield levels significantly from a genetic base has stymied researchers. This is so as most countries face a tremendous yield gap and the answer will not lie in merely breeding for enhanced yield but also to use strategies that are holistic, operate in tandem and have the provision to meet the targets set for both 2030 and 2050. Operating in this time frame where stresses shall dominate, new virulent races will emerge and resistances will be scarce to use as we saw over a decade ago for stem rust race UG99. Biotic stresses are dynamic and ever changing so the investigation drives will have to be very creative and this is where wide crossing has surfaced as an important arena. On the horizon is the newly observed rice blast and this offers similar challenges where resistance diversity is demanded and the search will ultimately lead to alien genetic resources that have allowed rice blast resistance to be identified in some D genome primary winter synthetic germplasm of the limited screened (Morgounov et al. 2017). There has to be caution that applied targets are not derailed and wide crossing is done just for academic purposes and its fine mettle as set via pre-breeding is diluted. Research must show prudence and smart vision that advances can be made easily by utilizing the diversity that has already been generated globally and is freely available. Hence attractive wide 
crossing ventures if associated with linkage drag delaying the progress. Thus alien sources for optimum quality usage are a smart way to combat what is needed for the decades ahead. An alien source may be excellent for usage like the highly salt tolerant Th. ponticum $(2 \mathrm{n}=10 \mathrm{x}=70)$ but due to its high polyploidy level it has been nearly three decades, and not even a single farmer ready salt tolerant variety has been released. This shows that lower polyploidy may be beneficial but even if we drop to the diploid level as in Th. bessarabicum and L. elongatum we find discourses supportive of the fact that the closest choice of alien resources lie in the D and followed by the A genome. Since time is tight and the demands acute the best option we recommend, is to use the diploid Ae. tauschii for direct crosses and there are over a 1000 synthetics available for pre-breeding. Almost all stresses can be addressed with the D genome synthetics (Mujeeb-Kazi et al. 2008, Ogbonnaya et al. 2013) and there are ample evidences in literature that suggest to stay clear of other counter effective resources for the applied scene when time demands and stress challenges are so acute and demanding applied varietal products.

\section{Conclusion}

Future food security is a major challenge for mankind, and studies of bread wheat improvement are of paramount significance. We have covered broadly a diversified look at the Triticeae genetic resources in this presentation as to their importance for wheat improvement The "how and why's" of exploitation are defined, protocols elucidated and facilitating tools described. We oversee that the pursuit of decades ahead will require a careful assessment of what research should focus diligently upon keeping a balance between time and delivery targets. The answer for food security is of course quantifiable and hence applied outputs that meet food needs of the increasing populace are to be kept at the forefront. In the early 20th century knowledge about hybrids and mutations was instrumental, more recently integrating breeding science with other disciplines such as environmental sciences will lead to a dramatic leap forward in plant breeding. Since the origin of agriculture, crop improvement has been a continuous process driven by the needs for improved quality or yield enhancements. Here breeding science directions are narrowed, that will be the preferential usage of translocations with less of the Robertsonian type, use of large spike wheats like Buitre with a group 7 translocation, exploiting the stay green character that is abundantly contributed by the $\mathrm{D}$ genome synthetics, take full advantage of the high 1000-grain weight of some D genome synthetics that ranges between 60 and 65 gms as compared to conventional wheats that rarely exceed 44 gms, selective emphasis on pentaploid breeding where the tetraploid parent possesses the yield attribute in its large grains like T. polonicum and 
adventurously capture the $\mathrm{F}_{1}$ hybrid heterotic vigor using doubled haploidy. Nonetheless, plant tissue culture will continue to play a significant role in wheat improvement, and in feeding the ever-increasing human population, facets that are discussed in this paper. The alien genomes have ample allelic diversity, often harnessed and preserved in globally available genetic stocks ready for usage but untapped. Time factor is to be kept at the forefront, the shift from basic to applied research will be dramatic, and one would get good competitive value advantage by using the right source for traits of choice as delineated in these investigations. The final test is always measured by the varietal outputs in farmers fields and bridging of the glaring yield gaps with creative use of alien resources and not to be lost in the haze of attractive basic science options.

\section{References}

Ahmad F and Comeau A (1990) Wheat $\times$ pearl millet hybridization: consequence and potential. Euphytica 50: 181-190.

Ali A, Arshad M, Naqvi SS, Rasheed A, Sher H, Kazi AG and Mujeeb-Kazi A (2015) Comparative assessment of synthetic-derived and conventional bread wheat advanced lines under osmotic stress and implications for molecular analysis. Plant Mol. Bio. Report 33(6): 1907-1917.

Ali I, Sardar Z, Rasheed A and Mahmood T (2015) Molecular characterization of the puroindoline- $a$ and $b$ alleles in synthetic hexaploid wheats and in silico functional and structural insights into Pina-D1. J. Theor. Biol. 376: 1-7.

Ali N, Heslop-Harrison JS, Ahmad H, Grayboch RA, Hein GL and Schwarzacher T (2016) Introgression of chromosome segments from multiple alien species in wheat breeding lines with wheat streak mosaic virus resistance. J. Heredity 117: 114-123.

Amagai Y, Watanabe N and Kuboyama T (2015) Genetic mapping and development of near-isogenic lines with genes conferring mutant phenotypes in Aegilops tauschii and synthetic hexaploid wheat. Euphytica 205(3): 859-868.

Anderson OD, Kuhl JC and Tam A (1996) Construction and expression of a synthetic wheat storage protein gene. Gene. 174(1): 51-8.

Almouslem AB, Jauhar PP, Peterson TS, Bommineni VR and Rao MB (1988) Haploid durum wheat production via hybridization with maize. Crop Sci. 38: 1080-1087.

Ashraf S, Shahzad A, Karamat F, Iqbal M and Ali GM (2015) Quantitative trait loci (QTLs) analysis of drought tolerance at germination stage in a wheat population derived from synthetic hexaploid and Opata. J. Animal and Plant Sci. 25(2): 539-545.

Bates LS and Deyoe CW (1973) Wide hybridization and cereal improvement. Econ. Bot. 27: 401-412.

Bahrman N and Thiellement H (1987) Parental genome expression in synthetic wheats (Triticum turgidum sp. $\times$ T. tauschii sp.) revealed by two-dimensional electrophoresis of seedling proteins. Theor. Appl. Genet. 74(2): 218-23. 
Becker SR, Byrne PF, Reid SD, Bauerle WL, McKay JK and Haley SD (2016) Root traits contributing to drought tolerance of synthetic hexaploid wheat in a greenhouse study. Euphytica 207(1): 213-224.

Calderini DF and Reynolds MP (2000) Changes in grain weight as a consequence of degraining treatments at pre-and post-anthesis in synthetic hexaploid lines of wheat (Triticum durum x T. tauschii). Func. Plant Biol. 27(3): 183-191.

Cossani CM and Reynolds MP (2015) Heat stress adaptation in elite lines derived from synthetic hexaploid wheat. Crop Sci. 55(6): 2719-2735.

Cox TS (1997) Deepening the wheat gene pool. J. Crop Prod. 1: 1-25.

Cox TS, Hatchett JH, Gill BS, Raupp WJ and Sears RS (1990) Agronomic performance of hexaploid wheat lines derived from direct crosses between wheat and Aegilops squarrosa. Plant Breeding 105: 271-277.

Cox TS and Hatchett JH (1994) Hessian fly-resistant gene H26 transferred from Triticumtauschiito common wheat. Crop Sci. 34: 958-960.

Cox TS, Raupp WJ and Gill BS (1994) Leaf rust resistant genes Lr41, Lr42, and Lr43 transferred from Triticum tauschii to common wheat. Crop. Sci. 34: 339-349.

Cox TS, Sears RG, Bequette RK and Martin TJ (1995a) Germplasm enhancement in winter wheat $\times$ Triticum aestivum backcross populations. Crop. Sci. 35: 913-919.

Cox TS, Sears RG and Bequette RK (1995b). Use of winter wheat x Triticum tauschii back-cross populations for germplasm evaluation. Theor. Appl. Genet. 90: 571-57.

Das M, Bai G, Mujeeb-Kazi A and Rajaram S (2015) Genetic diversity among synthetic hexaploid wheat accessions with resistance to several fungal diseases. Genet. Resour. Crop Evol. 63(8): 1285-1296.

Daskalova N, Doneva S and Spetsov P (2016) Chromosome variation and HMW glutenins in synthetic hexaploid wheats (Triticum turgidum ssp. dicoccum/Aegilops tauschii). Cereal Res. Commun. 44(3): 453-460.

Del Blanco IA, Rajaram S and Kronstad WE (2001) Agronomic potential of synthetic hexaploid wheat-derived populations. Crop Sci. 41(3): 670-676.

Del Blanco IA, Rajaram S, Kronstad WE and Reynolds MP (2000) Physiological performance of synthetic hexaploid wheat-derived populations. Crop Sci. 40(5): 12571263.

Dewey DR (1984) The genomic system of classification as a guide to intergeneric hybridization with the perennial Triticeae. In: Gustafson JP (ed) Gene manipulation in plant improvement. 16th Stadler Genetics Symp. Plenum, New York. pp. 209-279.

Dreisigacker S, Kishii M, Lage J and Warburton M (2008) Use of synthetic hexaploid wheat to increase diversity for CIMMYT bread wheat improvement. Crop Pasture Sci. 59(5): 413-420.

Dunckel SM, Olson EL, Rouse MN, Bowden RL and Poland JA (2015) Genetic Mapping of Race-Specific Stem Rust Resistance in the Synthetic Hexaploid W7984× Opata M85 Mapping Population. Crop Sci. 55(6): 2580-2588.

Dunckel S, Crossa J, Wu S, Bonnett D and Poland J (2016) Genomic Selection for Increased Yield in Synthetic-Derived Wheat. Crop Sci. 57(2): 713-725. 
Emebiri LC and Ogbonnaya FC (2015) Exploring the synthetic hexaploid wheat for novel sources of tolerance to excess boron. Mol. Breed. 35(2): 68.

Faheem M, Mahmood T, Shabbir G, Gul AG and Mujeeb-Kazi A (2015) Assessment of the D-genome based genetic diversity of drought tolerant wheat germplasm. Int. J. Agric. Biol. 17: 791-796.

Farrer W (1904). Some notes on the wheat "Bobs": its peculiarities, economic value, and origin. Agric. Gaz. NSW. 15: 849-854.

Frizon P, Brammer SP, Lima MIPM, Castro RLD and Deuner CC (2017) Genetic stability in synthetic wheat accessions: cytogenetic evaluation as a support in breeding programs. Ciência Rural 47(4).

Gedye KR, Morris CF and Bettge AD (2004) Determination and evaluation of the sequence and textural effects of the puroindoline a and puroindoline $b$ genes in $a$ population of synthetic hexaploid wheat. Theor. Appl. Genet. 109(8): 1597-1603.

Ghaemi M and Sarrafi A (1994) The effect of the "D" genome from synthetic wheat lines in anther culture responses. Plant Breeding 112(1): 76-9.

Gill BS and Raupp WJ (1987). Direct gene transfers fromAegilops squarrosa L. to hexaploid wheat. Crop. Sci. 27: 445-450.

Gorafi YS, Ishii T, Kim JS, Elbashir AAE and Tsujimoto H (2016) Genetic variation and association mapping of grain iron and zinc contents in synthetic hexaploid wheat germplasm. Plant Genet. Resour. 1-9. doi:10.1017/S1479262116000265

Gorham J (1990) Salt tolerance in the Triticeae: K/Na discrimination in synthetic hexaploid wheats. J. Exp. Bot. 41(226): 623-727.

Gul Kazi A, Rasheed A, Bux H, Napar AA, Ali A and Mujeeb-Kazi A (2015) Cytological, phenological and molecular characterization of $B(S)$-genome synthetic hexaploids ( $2 \mathrm{n}$ $=6 \mathrm{x}=42$; AABBSS). Cereal Res. Commun. 43(2): 179-88.

Gu L, Wei B, Fan R, Jia X, Wang X and Zhang X (2015) Development, identification and utilization of introgression lines using Chinese endemic and synthetic wheat as donors. J. Integr. Plant Biol. 57(8): 688-697.

Gul A, Rasheed A, Afzal F, Napar AA, Ali A, Jamil M and Mujeeb-Kazi A (2015) Characterization of Synthetic Hexaploids Derived from Same Aegilops tauschii Accessions and Different Durum Cultivars. Cytologia 80(4): 427-440.

Han F, Fedak G, Guo W and Liu B (2005) Rapid and repeatable elimination of a parental genome-specific DNA repeat (pGc1R-1a) in newly synthesized wheat allopolyploids. Genetics 170(3): 1239-1245.

Hatchett JH, Martin TJ and Livers RW (1981) Expression and inheritance of resistance to hessian fly in synthetic hexaploid wheats derived from Triticum tauschii (Coss) Schmal. Crop Sci. 21(5): 731-4.

Huang XQ, Cöster H, Ganal MW and Röder MS (2003) Advanced backcross QTL analysis for the identification of quantitative trait loci alleles from wild relatives of wheat (Triticum aestivum L.). Theor. Appl. Genet. 106(8): 1379-1389.

Huang XQ, Kempf H, Ganal MW and Röder MS (2004) Advanced backcross QTL analysis in progenies derived from a cross between a German elite winter wheat variety and a synthetic wheat (Triticum aestivum L.). Theor. Appl. Genet. 109(5): 933943. 
Iehisa JC and Takumi S (2012) Variation in abscisic acid responsiveness of Aegilops tauschii and hexaploid wheat synthetics due to the D-genome diversity. Genes Genet. Syst. 87(1): 9-18.

Ilyas M, Mahmood T, Ali A, Babar M, Rasheed A and Mujeeb-Kazi A (2015) Characterization of D-genome diversity for tolerance to boron toxicity in synthetic hexaploid wheat and in silico analysis of candidate genes. Acta Physiol. Plant. 37(2): 1-13.

Imtiaz M, Ogbonnaya FC, Oman J and van Ginkel M (2008) Characterization of quantitative trait loci controlling genetic variation for preharvest sprouting in synthetic backcross-derived wheat lines. Genetics 178(3): 1725-1736.

Inagaki MN,Pfeiffer WH, Mergoum M and Mujeeb-Kazi A (1998). Variation of the crossability of durum wheat with maize. Euphytica. 104: 17-23.

Inagaki M, Chaabane R and Bari A (2016) Root water-uptake and plant growth in two synthetic hexaploid wheat genotypes grown in saline soil under controlled water deficit stress. J. Plant Breeding Genet. 3(2): 49-57.

Islam AKMR, Shepherd KW and Sparrow DHB (1978) Production and characterization of wheat-barley addition lines. In: Proc. Of the 5th Int. Wheat Genet. Symposium, New Delhi, India. pp. 365-371.

Islam AKMR, Shepherd KW and Sparrow DHB (1981) Isolation and characterization of euplasmic wheat-barley chromosomal addition lines. J. Heredity 46: 161-174..

Jafarzadeh J, Bonnett D, Jannink JL, Akdemir D, Dreisigacker S and Sorrells ME (2016) Breeding Value of Primary Synthetic Wheat Genotypes for Grain Yield. PloS one. 11(9): e0162860.

Jiang JB, Friebe B and Gill BS (1994) Recent advances in alien gene transfer in wheat. Euphytica. 73: 199-212.

Jighly A, Alagu M, Makdis F, Singh M, Singh S, Emebiri LC and Ogbonnaya FC (2016) Genomic regions conferring resistance to multiple fungal pathogens in synthetic hexaploid wheat. Mol. Breeding 36(9): 127.

Kema GH, Lange W and Van Silfhout CH (1995) Differential suppression of stripe rust resistance in synthetic wheat hexaploids derived from Triticum turgidum subsp. dicoccoides and Aegilops squarrosa. Phytopathology 85(4): 425-9.

Khan Z, Qazi J, Rasheed A and Mujeeb-Kazi A (2016) Diversity in D-genome synthetic hexaploid wheat association panel for seedling emergence traits under salinity stress. Plant Genet. Resour. 1-8.

Kunert A, Naz AA, Dedeck O, Pillen K and Léon J (2007) AB-QTL analysis in winter wheat: I. Synthetic hexaploid wheat (T. turgidum ssp. Dicoccoides $\times$ T. tauschii) as a source of favourable alleles for milling and baking quality traits. Theor. Appl. Genet. 115(5): 683-695.

Kruse A (1967) Intergeneric hybridization between Hordeum vulgare L. ssp. distichum (v. Pallus, $2 \mathrm{n}=14$ ) and Secale cereale L (v. Petkus $2 \mathrm{n}=14$ ). Royal Veterinary Agricultural College Yearbook 1967. pp. $82-92$ (Copenhagen). 
Kruse A (1969) Intergeneric hybridization between Triticum aestivum L (v Koga II 2n = 42) and Avena sativa L ( $\mathrm{v}$ Stal $2 \mathrm{n}=42$ ) with pseudogamous seed formation. Royal Veterinary Agricultural College Yearbook 1969, pp 188-200 (Copenhagen).

Kruse A (1973) Hordeum x Triticum hybrids. Hereditas 73: 157-161.

Kruse A (1974a) A 2,4-D treatment prior to pollination eliminates the haplontic (gametic) sterility in wide intergeneric crosses with two-rowed barley. Hordeumvulgare ssp. distichum, as maternal species. Hereditas 78: 319.

Kruse A (1974b) Hordeum vulgare ssp distichum (var Bomi) × Triticum aestivum (var Koga). An F1 hybrid withgenerative seed formation. Hereditas 78: 319.

Laurie DA (1989) The frequency of fertilization in wheat $\times$ pearl millet crosses. Genome. 32: 1063-1067.

Lan X, Zheng Y, Ren X, Liu D, Wei Y and Yan Z (2004) Utilization of preharvest sprouting tolerance gene of synthetic wheat RSP. J. Plant Genet. Resour. 6(2): 204-209.

Laurie DA (1989). The frequency of fertilization in wheat x pearl millet crosses. Genome. 32:1063-1067.

Laurie DA and Bennett MD (1986) Wheat $\times$ maize hybridization. Can. J. Genet. Cytol. 28: 313-316.

Laurie DA and Bennett MD (1988a) Chromosome behaviour in wheat $x$ maize, wheat $x$ sorghum and barley $\times$ maize crosses. In: P.E. Brandham, ed., Kew Chromosome Conference III, Her Majesty's Stationary Office, London. pp. 167-177.

Laurie DA and Bennett MD (1988b)Cytological evidence for fertilization in hexaploid wheat $x$ Sorghum crosses. Plant Breeding 100: 73-82.

Laurie DA and Bennett MD (1988c)The production of haploid wheat plants from wheat $x$ maize crosses. Theor. Appl. Genet. 76: 393-397.

Laurie DA, O'Donoughue LS and Bennett MD (1990) Wheat $\times$ maize and otherwide sexual hybrids: their potential for crop improvement and geneticmanipulations. In: J.P. Gustafson, ed., Gene Manipulation in PlantImprovement II, Proc. 19th Stadler Genet. Symp. Plenum Press, New York. pp. 95-126.

Li J, Wan HS and Yang WY (2014) Synthetic hexaploid wheat enhances variation and adaptive evolution of bread wheat in breeding processes. J. Syst. Evol. 52(6): 735-742.

Li YF, Wu Y, Wang T, Li LR, Lu L, Zhang CY and Zheng S. G. (2015) Polyphenol oxidase activity and yellow pigment content in Aegilops tauschii, Triticum turgidum, Triticum aestivum, synthetic hexaploid wheat and its parents. J. Cereal Sci. 65: 192-201.

Liu, S, Zhou R, Dong Y, Li P and Jia J (2006) Development, utilization of introgression lines using a synthetic wheat as donor. Theor. Appl. Genet. 112(7): 1360-1373.

Liu W, Zheng MY, Polle EA and Konzak CF (2002) Highly efficient doubled-haploid production in wheat (Triticum aestivum L.) via induced microspore embryogenesis. Crop Sci. 42: 686-692.

Limin AE and Fowler DB (1993) Inheritance of cold hardiness in Triticum aestivum $\times$ synthetichexaploid wheat crosses. Plant Breeding 110(2): 103-8.

Lutz J, Hsam SL, Limpert E and Zeller FJ (1994) Powdery mildew resistance in Aegilops tauschii Coss. and synthetic hexaploid wheats. Genet. Resour. Crop Evol. 41(3): 151-8. 
Ma H, Singh RP and Mujeeb-Kazi A (1995a) Suppression/expression of resistance to stripe rust in synthetic hexaploid wheat (Triticum turgidum $x$ T. tauschii). Euphytica. 83: 87-93.

Ma H, Singh RP and Mujeeb-Kazi A (1995b) Resistance to stripe rust in Triticum turgidum, T. tauschii and their synthetic hexaploids. Euphytica 82(2): 117-24.

Ma YU, Chen GY, Zhang LQ, Liu YX, Liu DC, Wang JR and Liu CJ (2014) QTL mapping for important agronomic traits in synthetic hexaploid wheat derived from Aegiliops tauschii ssp. tauschii. J. Integr. Agric. 13(9): 1835-1844.

Mares D and Mrva K (2008) Genetic variation for quality traits in synthetic wheat germplasm. Crop Pasture Sci. 59(5): 406-412.

Masood R, Ali N, Jamil M, Bibi K, Rudd J and Mujeeb-Kazi A (2016) Novel genetic diversity of the alien D-genome synthetic hexaploid wheat $(2 n=6 x=42$, AABBDD) germplasm for various phenology tratis. Pak. J. Bot. 48(5): 2017-2024.

Matsuda R, Iehisa JC and Takumi S (2012) Application of real-time PCR-based SNP detection for mapping of Net2, a causal D-genome gene for hybrid necrosis in interspecific crosses between tetraploid wheat and Aegilops tauschii. Genes Genet. Syst. 87(2): 137-143.

McIntyre CL, Rattey A, Kilian A, Dreccer MF and Shorter R (2014) Preferential retention of chromosome regions in derived synthetic wheat lines: a source of novel alleles for wheat improvement. Crop Pasture Sci. 65(2): 125-138.

Mikó P, Megyeri M, Farkas A, Molnár I and Molnár-Láng M (2015) Molecular cytogenetic identification and phenotypic description of a new synthetic amphiploid, Triticum timococcum (AtAtGGAmAm). Genet. Resour. Crop Evol. 62(1): 55-66.

Mohsin T, Khan N and Naqvi FN (2009) Heritability, phenotypic correlation and path coefficient studies for some agronomic characters in synthetic elite lines of wheat. J. Food Agric. Environ 7(3\&4): 278-282

Morgounov A, Abugalieva A, Akan K, Akin B, Baenziger S, Bhatta M, Dadabai AA, Demir M, Duthayev Y, Bouhssini M El, Erginbas-Orakci G, Kishii M, Keser M, Koc E, Kurespek A, Mujeeb-Kazi A, Yorgancilar A, Ozdemir F, Ozturk I, Payne T, Qadimaliyeva G, Shamanin V, Subasi K,Suleymanova G, Yakisir E and Zelenskiy K (2017) High-yielding winter synthetic hexaploid wheats resistant to multiple diseases and pests. doi:10.1017/S147926211700017X. pp. 1-6.

Mettin D, Bluthner WD and Schlegel G (1973) Additional evidence on spontaneous 1B/ $1 \mathrm{R}$ wheat-rye substitutions and translocations. In: Sears, E.R., Sears, L.M.S. (Eds.), Proceedings of the Fourth International Wheat genetics Symposium, USA. pp. 179184.

Mujeeb-Kazi A, Thomas JB, Rodriguez R, Waters RF and Bates LS (1978) Chromosome instability in hybrids of Hordeum vulgare L. with Triticum turgidum and T. aestivum. J. Heredity. 69: 170-182.

Mujeeb-Kazi A and Rodríguez R (1980) Some intergeneric hybrids in the Triticeae. Cereal Res. Commun. 8: 469-475.

Mujeeb-Kazi A and Rodríguez R (1981) Cytogenetics of intergeneric hybrids involving genera within the Triticeae. Cereal Res. Commun. 9: 39-45. 
Mujeeb-Kazi A (1982)Some intergeneric hybrids involving wheat (Triticum aestivum L.): Production, description and practical utilization. Agronomy Abstracts. American Society of Agronomy. p. 77.

Mujeeb-Kazi A and Bernard (1985) Intergeneric hybridization to induce alien genetic transfers into Triticum aestivum. Pak. J. Bot. 17: 271-289.

Mujeeb-Kazi and Kimber G (1985) The production, cytology, and practicality of wide hybrids in the Triticeae. Cereal Res. Commun. 13: 111-124.

Mujeeb-Kazi A, Roldan S. Suh DY, Sitch LA and Farooq S (1987) Production and cytogenetic analysis of hybrids between Triticum aestivum and some caespitose Agropyron species. Genome 29: 537-553.

Mujeeb-Kazi A, Roldan S, Suh DY, ter-Kuile N and Farooq S (1989) Production and cytogenetics of Triticum aestivum L., hybrids with some rhizomatous Agropyron species. Theor. Appl. Genet. 77: 162-168.

Mujeeb-Kazi A. and Asiedu R (1990) Wide hybridization - potential of alien genetic transfers for Triticum aestivum improvement. In: Biotech in Agriculture and Forestry, Vol. 13, Wheat. Y.P.S. Bajaj (ed). pp. 111-127.

Mujeeb-Kazi A. and Hettel GP (1995) Utilizing wild grass biodiversity in wheat improvement: 15 years of wide cross research at CIMMYT. CIMMYT Research Report No. 2, 1995. pp.1-140.

Mujeeb-Kazi A, Rosas V and Roldan S (1996) Conservation of the genetic variation of Triticum tauschii (Coss.) Schmalh. (Aegilops squarrosa auct. non L.) in synthetic hexaploid wheats (T. turgidum L. s. lat. $x$ T. tauschii; $2 n=6 x=42$, AABBDD) and its potential utilization for wheat improvement.Genet. Resour. Crop Evol. 43(2): 129-34.

Mujeeb-Kazi A, Cano S, Rosas V, Cortes A and Delgado R (2001a) Registration of five synthetic hexaploid wheat and seven bread wheat lines resistant to wheat spot blotch. Crop Sci. 41(5): 1653-1653.

Mujeeb-Kazi A, Fuentes-Davila G, Villareal RL, Cortes A, Rosas V and Delgado R (2001b). Registration of 10 synthetic hexaploid wheat and six bread wheat germplasms resistant to karnal bunt. Crop Sci. 41(5): 1652-1652.

Mujeeb-Kazi A (2003) New genetic stocks for durum and bread wheat improvement. Tenth International Wheat Genetics Symposium, Paestum, Italy. pp. 772-774.

Mujeeb-Kazi A and van-Ginkel M (2004) Genetic resources: Extent of diversity, its usage, and purpose for wheat improvement. Plant and Animal Genome XII Conference, San Diego, California. p. 51.

Mujeeb-Kazi A., Gul A, Ahmad J and Mirza JI (2006) A simplified and effective protocol for production of bread wheat haploids $(n=3 x=21$, ABD) with some application areas in wheat improvement. Pak. J. Bot. 38: 393-406.

Mujeeb-Kazi A, Gul A, Farooq M, Rizwan S and Ahmad I (2008) Rebirth of synthetic hexaploids with global implications for wheat improvement. Crop Pasture Sci. 59(5): 391-398. 
Mujeeb-Kazi A., Kazi AG, Dundas I, Rasheed A, Ogbonnaya F, Chen P, Kishi M, Bonnett D, Wang RR-C, Xu S, Bux H, Mahmood T and Farrakh S (2013) Genetic Diversity for Wheat Improvement as a Conduit for Food Security. Adv. in Agronomy 122: 179-259.

Narasimhamoorthy B, Gill BS, Fritz AK, Nelson JC and Brown-Guedira GL (2006) Advanced backcross QTL analysis of a hard winter wheat $\times$ synthetic wheat population. Theor. Appl. Genet. 112(5): 787-796.

Nei M (1963) The efficiency of haploid method of plant breeding. Heredity 18: 95-100.

Nguyen AT, Iehisa JCM, Kajimura T, Murai K and Takumi S (2013) Identification of quantitative trait loci for flowering-related traits in the $\mathrm{D}$ genome of synthetic hexaploid wheat lines. Euphytica 192(3): 401-412.

Nguyen AT, Nishijima R, Kajimura T, Murai K and Takumi S (2015) Quantitative trait locus analysis for flowering-related traits using two F2 populations derived from crosses between Japanese common wheat cultivars and synthetic hexaploids. Genes Genet. Syst. 90(2): 89-98.

O'Donoughue LS and Bennett MD (1988) Wide hybridization between relativesof bread wheat and maize. In pages 397-402, T.E. Miller and R.M.D. Koebner, Eds. Proc. 7th International Wheat Genetics Symposium, Cambridge, U.K.

Nicholson P, Rezanoor HN and Worland AJ (1993) Chromosomal location of resistance to Septoria nodorum in a synthetic hexaploid wheat determined by the study of chromosomal substitution lines in 'Chinese Spring' wheat. Plant Breeding 110(3): 17784.

Ogbonnaya FC, Abdalla O, Mujeeb-Kazi A, Kazi AG, Xu SS, Gosman N and Tsujimoto $\mathbf{H}$ (2013) Synthetic hexaploids: harnessing species of the primary gene pool for wheat improvement. Plant Breeding Rev. 37: 35-122.

Pagani APS, Dianese AC and Café-Filho AC (2014) Management of wheat blast with synthetic fungicides, partial resistance and silicate and phosphite minerals. Phytoparasitica 42(5): 609-617.

Pflüger LA, D'Ovidio R, Margiotta B, Pena R, Mujeeb-Kazi A and Lafiandra D (2001) Characterisation of high-and low-molecular weight glutenin subunits associated to the D genome of Aegilops tauschii in a collection of synthetic hexaploid wheats. Theor. Appl. Genet. 103(8): 1293-1301.

Phillips RL, Rines HW, Kyanst RG, Okagaki RJ, Galatowitsch MW, Jacobs MS, Stec AO, Schmidt CM, Retzel EF and Odland WE (2004). Chromosome dynamics in oatmaize addition lines and derivatives. Plant and Animal Genome XII Conference, San Diego, California. pp. 52.

Plamenov D and Spetsov P (2011) Synthetic hexaploid lines are valuable resources for biotic stress resistance in wheat improvement. J. Plant Pathol. 251-262.

Pritchard DJ, Hollington PA, Davies WP, Gorham J, de Leon JD and Mujeeb-Kazi A (2002) $\mathrm{K}^{+} / \mathrm{Na}^{+}$discrimination in synthetic hexaploid wheat lines: Transfer of the trait for $\mathrm{K}^{+} / \mathrm{Na}^{+}$discrimination from Aegilops tauschii into a Triticum turgidum background. Cereal Res. Commun. 30: 261-267. 
Qadir A, Ilyas M, Akhtar W, Aziz E, Rasheed A and Mahmood T (2015). Study of genetic diversity in synthetic hexaploid wheats using random amplified polymorphic DNA.J. Animal Plant Sci. 25(6): 1660-1666.

Qiang R, HuiJuan L, Yang C, ShiChang X, MingZhao H, ZhiYong X and ZengYan Z (2010) Molecular tagging of a stripe rust resistance gene in a Triticum durumAegilopssquarrosa synthetic wheat CI191. Acta Agronomica Sinica. 36(5): 721-727.

Qu, LJ, Foote TN, Roberts MA, Money TA, Aragon-Alcaide L, Snape JW and Moore G (1998) A simple PCR-based method for scoring the ph1b deletion in wheat. Theor. Appl. Genet. 96: 371-375.

Rajaram S, Mann ChE, Ortiz-Ferrara G and Mujeeb-Kazi A (1983) Adaptation, stability and high yield potential of certain 1B/1R CIMMYT wheats. In: Proc. 6th. Int. Wheat Genetic Symposium, Sakamoto, S. (Eds.), Kyoto, Japan. pp. 613-621.

Rana RM, Bilal M, Rehman SU, Iqbal F and Shah MKN (2013) Synthetic wheat; a new hope for the hungry world. Asian J. Agric. Bio. 1(2): 91-94.

Rasheed A, Xia X, Ogbonnaya F, Mahmood T, Zhang Z, Mujeeb-Kazi A and He Z (2014) Genome-wide association for grain morphology in synthetic hexaploid wheats using digital imaging analysis. BMC Plant Biology 14(1): 128.

Riera-Lizarazu O and Mujeeb-Kazi A (1990) Maize (Zea mays L.) mediated wheat (Triticum aestivum L.) polyhaploid production using various crossing methods. Cereal Res. Commun. 18: 339-345.

Rimpau W (1891). Kreuzungsprodukte landwirtschaftlicher Kulturpflanzen. Landwirtsch Jahrb 20:335-371.

Rupp JLS, Simon ZG, Gillett-Walker B and Fellers JP (2014) Resistance to Wheat streak mosaic virus identified in synthetic wheat lines. Euphytica 198(2): 223-229.

Sears ER (1977) An induced mutant with homoeologous pairing in common wheat. Can. J. Gent. Cytol. 19: 585-593.

Sharma HC and Gill BS (1983a) Current status of wide hybridization in wheat. Euphytica. 32: 17-31.

Sharma HC and Gill BS (1983b) New hybrids between Agropyron and wheat. 2 Production, morphology and cytogenetic analysis of F, hybrids and backcross derivatives. Theor. Appl. Genet. 66: 111-121.

Sharma HC and Gill BS (1983c) New hybrids between Agropyron and wheat. III Backcross derivatives, effect of Agropyron cytoplasm, and production of addition lines. In: Proc 6th IWG Symp, Kyoto, Jpn, pp. 213-221.

Sharma HC and Gill BS (1986) The use of $p h 1 b$ gene in direct transfer and search for $\mathrm{Ph}$ like genes in polyploid Aegilops species. Z. Pflanzenzüchtg, 96: 1-7.

Sharma HC (1995). How wide can a wide cross be? Euphytica 82: 43-64.

Sharma M, Kaur S, Saluja M and Chhuneja P (2016) Mapping and characterization of powdery mildew resistance gene in synthetic wheat. Czech J. Genet. Plant Breeding 52(3): 120-123.

Sharma P, Sareen S, Saini M, Verma A, Tyagi BS and Sharma I (2014) Assessing genetic variation for heat tolerance in synthetic wheat lines using phenotypic data and molecular markers. Aust. J. Crop Sci. 8(4): 515. 
Siedler H, Obst A, Hsam SL and Zeller FJ (1994) Evaluation for resistance to Pyrenophora tritici-repentis in Aegilops tauschii Coss. and synthetic hexaploid wheat amphiploids. Genet. Resour. Crop Evol. 41(1): 27-34.

Sotelo P, Starkey S, Voothuluru P, Wilde GE and Michael Smith C (2009) Resistance to Russian wheat aphid biotype 2 in CIMMYT synthetic hexaploid wheat lines. J. Econ. Ento. 102(3): 1255-1261.

Suenaga K and Nakajima K (1989) Efficient production of haploid wheat (Triticum aestivum) through crosses between Japanese wheat and maize (Zea mays). Plant Cell Rep. 8: 263-266.

Tadesse W, Hsam SL, Wenzel G and Zeller FJ (2006) Identification and monosomic analysis of tan spot resistance genes in synthetic wheat lines (L.x Coss.). Crop sci. 46(3): 1212-1217.

Tadesse W, Schmolke M, Hsam SLK, Mohler V, Wenzel G and Zeller FJ (2007) Molecular mapping of resistance genes to tan spot [Pyrenophora tritici-repentis race 1] in synthetic wheat lines. Theor. Appl. Genet. 114(5): 855-862.

Takumi S, Naka Y, Morihiro H and Matsuoka Y (2009) Expression of morphological and flowering time variation through allopolyploidization: an empirical study with 27 wheat synthetics and their parental Aegilops tauschii accessions. Plant Breeding 128(6): 585-590.

Tang YL, Li CS, Yang WY, Wu YQ, Wu XL, Wu C and Rosewarne GM (2016) Quality potential of synthetic-derived commercial wheat cultivars in south-western China. Crop Pasture Sci. 67(6): 583-593.

Tang Y, Rosewarne GM, Li C, Wu X, Yang W and Wu C (2015) Physiological factors underpinning grain yield improvements of synthetic-derived wheat in Southwestern China. Crop Sci. 55(1): 98-112.

Trethowan RM and van Ginkel M (2009) Synthetic wheat - an emerging genetic resource. In: Carver B. (ed.). Wheat -Science and Trade, pp. 369-386. Wiley-Blackwell, Ames, IO, USA.

Trethowan RM and Mujeeb-Kazi A (2008) Novel germplasm resources for improving environmental stress tolerance of hexaploid wheat. Crop Sci. 48(4): 1255-1265.

Trethowan RM and van Ginkel M (2009) Synthetic wheat-an emerging genetic resource. Carver BF Wheat, science and trade. pp. 369-386.

Trethowan RM, Borja J and Mujeeb-Kazi A (2003) The impact of synthetic wheat on breeding for stress tolerance at CIMMYT (No. CIS-3786. CIMMYT).

Ushiyama T, Shimizu T and Kuwabara T (1991) High frequency of haploid production of wheat through intergeneric cross with Teosinte. Japan J. Breed. 41: 353-357.

van Ginkel M and Ogbonnaya F (2007) Novel genetic diversity from synthetic wheats in breeding cultivars for changing production conditions. Field Crops Res. 104(1): 86-94.

Villareal RL, Mujeeb-Kazi A, Fuentes-Davila G, Rajaram S and Toro ED (1994) Resistance to karnal bunt (Tilletia indica Mitra) in synthetic hexaploid wheats derived from Triticum turgidum $\times$ T. tauschii. Plant Breeding 112(1): 63-9. 
Villareal RL, Sayre K, Banuelos O and Mujeeb-Kazi A (2001) Registration of four synthetic hexaploid wheat (Triticum turgidum/Aegilops tauschii) germplasm lines tolerant to waterlogging. Crop Sci. 41(1): 274-274.

Wang J, Liao XZ, Yang XJ, Zhou RH and Jia JZ (2008) Mapping of large-spike and muchkernel QTL by using a synthetic wheat Am3 as donor. J. Plant Genet. Res. 9(3): 277282.

Wang L, Zhang Z, Liu H, Xu S, He M, Liu H and Xin Z (2009) Identification, gene postulation and molecular tagging of a stripe rust resistance gene in synthetic wheat CI142. Cereal Res. Commun. 37(2): 209-215.

Wang RRC (1989) Intergeneric hybrids involving perennial Triticeae. Genetics (Life Sci. Adv.) 8: 57-64.

Wang T, Xu SS, Harris MO, Hu J, Liu L and Cai X (2006) Genetic characterization and molecular mapping of Hessian fly resistance genes derived from Aegilops tauschii in synthetic wheat. Theor. Appl. Genet. 113(4): 611-618.

Wang YJ, Wang CY, Zhang H, Ali M, Xue F, Liu XL and Ji, WQ (2015) Molecular mapping of stripe rust resistance gene YrSE5756 in synthetic hexaploid wheat and its transfer to common wheat. Pak. J. Bot. 47(3): 1183-1189.

Wang Y, Wang C, Quan W, Jia X, Fu Y, Zhang H and Ji W (2016) Identification and mapping of PmSE5785, a new recessive powdery mildew resistance locus, in synthetic hexaploid wheat. Euphytica 207(3): 619-626.

Xiu-Jin L, Deng-Cai L and Zhi-Rong W (1997) Inheritance in synthetic hexaploid wheat 'RSP' of sprouting tolerance derived from Aegilops tauschii Cosson. Euphytica 1 95(3): 321-3.

Xu SS, Friesen TL and Mujeeb-Kazi A (2004) Seedling resistance to tan spot and Stagonospora nodorum blotch in synthetic hexaploid wheats. Crop Sci. 44(6): 22382245.

Yang W, Liu D, Li J, Zhang L, Wei H, Hu X and Zou Y (2009) Synthetic hexaploid wheat and its utilization for wheat genetic improvement in China. J. Genet. Genom. 36(9): 539-546.

Yokota H, Iehisa JC, Shimosaka E and Takumi S (2015) Line differences in Cor/Lea and fructan biosynthesis-related gene transcript accumulation are related to distinct freezing tolerance levels in synthetic wheat hexaploids. J. Plant Physio. 176: 78-88.

Zegeye H, Rasheed A, Makdis F, Badebo A and Ogbonnaya FC (2014) Genome-wide association mapping for seedling and adult plant resistance to stripe rust in synthetic hexaploid wheat. PLoS One 9(8): e105593.

Zeng D, Luo J, Li Z, Chen G, Zhang L, Ning S and Liu D (2016) High transferability of homoeolog-specific markers between bread wheat and newly synthesized hexaploid wheat lines. PloS one 11(9): e0162847.

Zenkteler M and Nitzsche W (1984) Wide hybridization experiments in cereals. Theor. Appl. Genet. 68: 311-315.

Zhang L, Liu D, Lan X, Zheng Y and Yan Z (2008) A synthetic wheat with 56 chromosomes derived from Triticum turgidum and Aegilops tauschii. J. Appl. Genet. 49(1): 41-44. 
Zhu Z, Bonnett D, Ellis M, He X, Heslot N, Dreisigacker S and Singh P (2016) Characterization of Fusarium head blight resistance in a CIMMYT synthetic-derived bread wheat line. Euphytica 208(2): 367-375.

Zhu Z, Bonnett D, Ellis M, Singh P, Heslot N, Dreisigacker S and Mujeeb-Kazi A (2014) Mapping resistance to spot blotch in a CIMMYT synthetic-derived bread wheat. Mol. Breeding 34(3): 1215-1228. 